D. L. peña, V. Albero, C. Ibáñez, A. Hospitaler. Sectional model for the fire evaluation of reinforced concrete columns subjected to biaxial bending. Engineering Structures 2021; 247: 113094. https://doi.org/10.1016/j.engstruct.2021.113094

\title{
Sectional model for the fire evaluation of reinforced concrete columns
}

\section{subjected to biaxial bending}

\author{
D. L.Peña ${ }^{a}$, V. Albero ${ }^{b}, C$. Ibáñez $^{\mathrm{a}^{*}}$, A. Hospitaler ${ }^{\mathrm{a}}$ \\ ${ }^{a}$ Department of Construction Engineering and Civil Engineering Projects, Universitat \\ Politècnica de València, Valencia, Spain \\ ${ }^{b}$ Department of Mechanical Engineering and Construction, Universitat Jaume I, \\ Castellón, Spain \\ *Corresponding author.caribus@upv.es
}

\begin{abstract}
In this work a simplified model for evaluating the cross-sectional capacity of RC columns subjected to biaxial bending and fire is presented. In order to build the simplified model, a fiber based numerical model is developed as a tool to obtain the cross-sectional interaction diagrams in $2 \mathrm{D}$ or $3 \mathrm{D}$. For the determination of the temperature field of the section during fire exposure the finite differences method is employed. The fiber model is validated against experimental and numerical data for $\mathrm{RC}$ short rectangular columns and their predictions are compared with those given by a numerical model. The influence of the concrete compressive strength, the concrete cover, the reinforcement ratio and its arrangement on the fire capacity of RC columns subjected to combined axial and biaxial bending is investigated through a parametric study. Finally, the simplified model based on the Bresler's equation is developed and validated, and its straightforward application for daily practice is illustrated by means of a worked example.
\end{abstract}

Keywords: Fire resistance; Reinforced concrete columns; Biaxial bending; Simplified model; Fiber model. 
D. L. peña, V. Albero, C. Ibáñez, A. Hospitaler. Sectional model for the fire evaluation of reinforced concrete columns subjected to biaxial bending. Engineering Structures 2021; 247: 113094. https://doi.org/10.1016/j.engstruct.2021.113094

\section{NOTATION}

$A_{c} \quad$ Concrete area

As $\quad$ Reinforcing bars area

$A_{s, c} \quad$ Area of reinforcing bars placed at the corners of the section

$A_{s, c} / A_{s} \quad$ Reinforcement arrangement ratio

$\exp \quad$ Result obtained by experimental tests (subscript)

$e_{y} \quad \mathrm{y}$-axis eccentricity

$e_{z} \quad$ z-axis eccentricity

$f_{\mathrm{c}} \quad$ Concrete compressive strength

$f_{\mathrm{y}} \quad$ Yield strength of steel reinforcing bars

model Result given by the simplified model proposed (subscript)

$M_{d 2} \quad$ Maximum bending moment resistance at direction $\beta$

My Applied bending moment in y-axis

$M_{z} \quad$ Applied bending moment in z-axis

$n_{c} \quad$ Nondimensional axial force in compression

$n_{t} \quad$ Nondimensional axial force in tension

$N \quad$ Applied axial load

$N_{d 2} \quad$ Axial force at maximum bending moment

$N_{\max } \quad$ Maximum value of the cross-sectional resistance

fiber Result given by the numerical fiber model (subscript)

$N_{u c} \quad$ Ultimate axial load in compression

$N_{u t} \quad$ Ultimate axial load in tension

$P_{m, n} \quad$ Thermal mesh calculation point $(\mathrm{m}, \mathrm{n})$

$u_{s} \quad$ Reinforcement concrete cover 
D. L. peña, V. Albero, C. Ibáñez, A. Hospitaler. Sectional model for the fire evaluation of reinforced concrete columns subjected to biaxial bending. Engineering Structures 2021; 247: 113094. https://doi.org/10.1016/j.engstruct.2021.113094

$V_{r} \quad$ Volume enclosed by the 3D interaction surface

$\alpha \quad$ Neutral axis angle

$\beta \quad$ Rotation angle

$\Delta \xi \quad$ thermal mesh size (square dimension)

$\varepsilon_{\mathrm{c}} \quad$ maximum compressive strain

$\varepsilon_{\mathrm{t}} \quad$ maximum tension strain

$\eta \quad$ Bresler's exponent

$\kappa \quad$ Curvature

$\xi_{3 \mathrm{D}} \quad$ Three-dimensional error

$\xi \quad$ Generatrix coefficient for the descending branch

$\tau \quad$ Generatrix coefficient for the ascending branch

$\omega \quad$ Reinforcement ratio $\left(\omega=A_{s} f_{y} / A_{c} f_{c}\right)$ 
D. L. peña, V. Albero, C. Ibáñez, A. Hospitaler. Sectional model for the fire evaluation of reinforced concrete columns subjected to biaxial bending. Engineering Structures 2021; 247: 113094. https://doi.org/10.1016/j.engstruct.2021.113094

\section{INTRODUCTION}

Concrete is chosen in structural projects for several reasons but one of the most important inherent benefits is its performance in fire situation due to its non-combustibility and its low thermal diffusivity (slow rate of heat transfer). As a consequence, in most cases, concrete does not require any additional protection, since these characteristics make concrete structures an effective barrier to the spread of fire.

Functional requirements of a real building make that the common loading situations for reinforced concrete $(\mathrm{RC})$ columns may be compression combined with biaxial bending due to the load transferred from adjacent beams and slabs. In addition, when a RC column is nonuniformly exposed to fire, the sectional temperature field becomes non-symmetric, which also happens when spalling occurs (Fig. 1). This situation leads also to a biaxial bending loading condition. The difficulty to obtain the ultimate capacity of the RC section increases under these circumstances.

Given the complexity that implies the study of biaxial bending combined with the sectional heating, the number of research works found in literature about the fire design of RC columns under these loading conditions is very limited. As presented in the next section, a review of the literature about the analysis and design models highlights the lack of methods to calculate this type of elements, even in the current codes.

In this paper, a simplified calculation model for biaxially loaded RC sections in fire is presented. The proposal is the result of a curve fitting procedure made from numerical results given by a fiber numerical model developed by the authors. 
D. L. peña, V. Albero, C. Ibáñez, A. Hospitaler. Sectional model for the fire evaluation of reinforced concrete columns subjected to biaxial bending. Engineering Structures 2021; 247: 113094. https://doi.org/10.1016/j.engstruct.2021.113094

\section{STATE OF THE ART}

In the current codes, the analysis and design approaches focus mainly in the analysis under compression loads and uniaxial bending. At ambient temperature, to face the analysis of RC columns subjected to biaxial bending, EN 1992-1-1 [1] suggests a simplified method based on the failure surfaces criteria presented previously by Bresler [2]. For ambient temperature design, numerical methods have been developed as tools to evaluate the capacity of RC sections subjected to biaxial loads. To avoid the numerical integration of concrete stresses, simplified methods are presented as an alternative. Several types of simplified methods can be found, such as for example methods that approximate the failure surface of a section analytically. The method proposed by Bresler [2] belongs to this typology. In this method, the failure surface for a RC section is approximated by sections at constant axial load given by a proposed load contour equation. Through the years, and given the need for research in this field, several authors have worked on the development of analytical and numerical methods for the calculation of RC columns subjected to biaxial bending ([3][4][5][6][7][8]). Among these, the work published by Bonet et al. [6] was based on the method presented by Bresler. The authors [6] proposed to obtain the failure surface of a biaxially loaded RC section by means of reference generatrices which stand on two directrix curves, which makes the method easy to use in practical applications.

At high temperatures, the determination of the cross-sectional temperature distribution does not facilitate the development of simplified methods. For RC columns subjected to compression and uniaxial bending, some works are available in the literature [7]. Bamonte et al. [8] described an approach that extends the limit-analysis method to be used also in fire situation. Law and Gillie [9] presented a proposal to obtain M-N surfaces for ambient and heated RC sections based on the tangent modulus method. In the same line, Caldas et al. [10] 
D. L. peña, V. Albero, C. Ibáñez, A. Hospitaler. Sectional model for the fire evaluation of reinforced concrete columns subjected to biaxial bending. Engineering Structures 2021; 247: 113094. https://doi.org/10.1016/j.engstruct.2021.113094

developed a procedure to obtain the $\mathrm{M}-\mathrm{N}$ interaction curves for generic $\mathrm{RC}$ and composite sections subjected to an arbitrary temperature field. An extensive set of formulas for the construction of integration diagrams with the estimation of the average temperature distribution and the corresponding internal forces was proposed by El-Fitiany and Yousef [11] for fireexposed RC sections. More recently, Pham et al. [12] applied the yield-design approach to determine the M-N interaction diagrams of reinforced concrete sections under combined axial load and bending moment in fire. According to the authors, the method can be easily extended to biaxial bending although the validation is not presented.

In fact, given its complexity, the number of research works about the fire design of RC columns under biaxial bending is still limited. Besides, the European code EN 1992-1-2 [13] does not include any specific simplified design model for biaxially loaded RC columns subjected to fire either. Taking as reference the ambient temperature method proposed in EN 1992-1-1 [1] (originally from Bresler [2]), Wang et al. [14] evaluated its applicability in the fire situation through a previously validated model with experimental results obtained by Tan and Nguyen [15]. Particularly, for 4-sided exposed RC columns subjected to the ISO834 standard temperature-time curve, Wang et al. [14] defined the powers of the non-dimensional interaction equation as a function of the steel reinforcement ratio, the number of reinforcing bars, the concrete cover, the column dimensions and the fire duration. In the same line, Kodur and Raut [16] carried out a numerical study on the fire capacity of RC columns under biaxial bending and evaluated the influence of non-symmetric fire exposures (one, two and three sides) and spalling. A numerical study was carried out and, after a parametric analysis, an equation was proposed and validated with experimental data.

Buch and Sharma [17] in their recent work presented a meta-analysis on data from 155 $\mathrm{RC}$ columns available on previous published works with the purpose of analysing the influence of different parameters. The study shows that there is a necessity for addressing the fire 
D. L. peña, V. Albero, C. Ibáñez, A. Hospitaler. Sectional model for the fire evaluation of reinforced concrete columns subjected to biaxial bending. Engineering Structures 2021; 247: 113094. https://doi.org/10.1016/j.engstruct.2021.113094

resistance of RC columns considering the role of various reinforcement layouts under eccentric loading. The conclusions of the authors were used for the design of an experimental program. These conclusions corroborated the observations reported by Kodur and Raut [16] who stated that thermal gradients are higher in eccentrically loaded columns but that their effect under eccentric loads for different reinforcement patterns is poorly documented. The influence of the reinforcement layout had been already reported by Dottrepe et al. [18], who stated the clear influence of the number of longitudinal bars in the fire resistance of RC columns.

It should be noted that calculation methods are presented in the current standards and available literature (e.g. Tan and Yao [19]) for assessing RC columns in fire exposed to bending moment and axial load. In the current code EN 1992-1-2 [13], guidelines can be found in Clause 5.3 or Annex B.3. It is very well known the $500^{\circ} \mathrm{C}$ isotherm method which comprises the no contribution to the load bearing capacity of the external cross-sectional area whose temperature is higher than $500^{\circ} \mathrm{C}$. Extrapolating this method for fire design of biaxially loaded RC members is not straightforward. In fact, without a numerical model it is difficult to obtain the neutral axis position and cross-sectional balance of forces. The lack of simplified methods for assessing the fire capacity of biaxially loaded RC sections is evident. Practitioners nowadays are required to use computationally intensive numerical models to solve this problem. To this end, the development of a simple calculation model to assess the biaxial bending failure of RC crosssections in fire, when ultimate capacity is already known under axial or uniaxial bending loads, may be useful in practice.

Therefore, in this work a simplified model (SM) for evaluating the cross-sectional capacity of RC columns subjected to biaxial bending and fire is presented. The SM gives the capacity of RC short columns in which second order effects do not appear and their response is governed by their sectional behaviour. The SM is based on the analytical failure surface definition, using generatrix and directrix curves as a reference, as was already presented at room 
D. L. peña, V. Albero, C. Ibáñez, A. Hospitaler. Sectional model for the fire evaluation of reinforced concrete columns subjected to biaxial bending. Engineering Structures 2021; 247: 113094. https://doi.org/10.1016/j.engstruct.2021.113094

temperature by Bonet et al. [6]. In order to build the SM, an advanced fiber based numerical model (FM) is developed to obtain the cross-sectional interaction diagrams in 2D or 3D (section 3.1). For the determination of the temperature field of the section at elevated temperatures the finite difference method is used. The FM is validated (section 3.2 and 3.3) against experimental and numerical data for RC short rectangular columns and their predictions are compared with those given by other advanced numerical models.

In turn, a parametric study is developed (section 4.1) using the advanced FM to extend the available failure points from the scarce experimental ones. The results of the parametric study (section 4.2) are used to evaluate the influence of the arrangement of the reinforcement, and the concrete cover on the fire capacity of RC columns subjected to combined axial and biaxial bending. This is then used to build the simplified method (section 5), based on the definition of the analytical failure envelope. Finally, a worked example (section 6) of the proposed SM for RC cross-sections in fire under biaxial bending is included to detail the usage of this method in practice.

Note that for ambient temperature and arbitrary sections, Chen et al. [20] proposed algorithms for the analysis of the moment-curvature. The algorithm used in the present paper to obtain the moment-curvature curves has the same basis as the convergence algorithm presented in [20]. The key difference arises when the fire situation is taken into account, since the temperature dependent material properties (thermal and mechanical) and the consideration of thermal strains must be adopted, which add more nonlinearities to the problem resolution.

It is important to highlight that the modelling of spalling with the numerical model has not been included in this paper. However, the authors have been working in parallel in the modelling of spalling with the FM as can be consulted in [21]. So far, the preliminary results indicate that the effect of spalling in a reinforced concrete cross-section can be equivalent to 
D. L. peña, V. Albero, C. Ibáñez, A. Hospitaler. Sectional model for the fire evaluation of reinforced concrete columns subjected to biaxial bending. Engineering Structures 2021; 247: 113094. https://doi.org/10.1016/j.engstruct.2021.113094

the effect of extending the duration of heating for several minutes on the same reinforced concrete cross-section without the occurrence spalling.

Also, it is worth noting that when a structural member, in this case a RC column, is subjected to a fire there is a loss of stiffness. The different level of stiffness of the heated member and the adjacent colder ones (other columns and beams) generates also restraints to axial and rotational deformations. All of this leads to variations in the supported loads which, inevitably, will affect the capacity of the column. In order to revise this effect, the interaction column-structure should be analysed, which is not considered in this work where the study focus on the cross-sectional behaviour. Substructures or structures, and not only the isolated structural member, should be investigated to that end.

\section{NUMERICAL FIBER MODEL}

\subsection{Numerical fiber model description}

A sequentially coupled thermal-stress analysis is accomplished by means of a numerical fiber model (FM) developed in the Matlab [22] platform. This consists of two steps: first, a sectional thermal analysis is carried out to compute the temperature field of the cross-section for a given fire exposure time and subsequently, a mechanical problem is solved. For clarity, Fig. 2 shows a flowchart of the FM steps. The use of this fiber based approach to study the fire resistance of RC columns can be found in several works (e.g. [8][10][11][14]).

For the main heat transfer parameters, the values recommended in EN 1991-1-2 [23] are used. The standard temperature-time curve is applied to the exposed surface through convection and radiation. In this case, for the concrete and the reinforcing steel bars, the thermal and mechanical properties given by EN 1992-1-2 [13] are employed. When not specified in the literature, siliceous aggregates are considered. The numerical FM developed would be considered as an advanced method using the terminology introduced earlier in this paper. The 
D. L. peña, V. Albero, C. Ibáñez, A. Hospitaler. Sectional model for the fire evaluation of reinforced concrete columns subjected to biaxial bending. Engineering Structures 2021; 247: 113094. https://doi.org/10.1016/j.engstruct.2021.113094

effects of transient creep strains are taken into account within this model as the EN 1992-1-2 [13] material model for concrete, which implicitly considers transient creep strains, is employed.

To obtain the cross-sectional temperatures, the finite differences method proposed by Lie and Irwin [24] is applied. The discretisation of the section for the thermal model is shown in Fig. 3. The cross-section is divided in rhombus whose centroid is the point representing the cell. The elements near the perimeter of the section are triangles and the representative point lies on the edge, in the mid-length of the hypotenuse. For a four sided exposed element, given the symmetry of the problem, it would be enough to perform the analysis in a quarter of the section.

For the mechanical analysis, the cross-section is discretised with a triangular mesh (Fig. 4a) where each cell is characterised by its position, its temperature (obtained by linear interpolation from the previously determined temperature field) and by the corresponding material properties.

The Navier-Bernoulli assumption is adopted, which states that a plane section remains plane and normal to the neutral axis (Fig. 4a) after bending. Therefore, the curvature of the cross-section $(\kappa)$ can be derived from the linear distribution of total strains (in this work, mechanical strains are equal to total strains minus thermal strains). The stress state of each cell is obtained from the constitutive equation of the material at the corresponding temperature. For a given applied load $N$ and through an iterative process, the location of the neutral axis is determined based on the force balance equation given in Eq. (1).

$$
\sum_{i=1}^{n} A_{i} \sigma_{i}-N=0
$$

$A=\frac{\sqrt{\sigma^{2}}}{\Omega}$ ewhere $A_{i}$ is the area of cell $\mathrm{i}\left(\mathrm{mm}^{2}\right) ; \sigma_{i}$ is the stress of cell $\mathrm{i}\left(\mathrm{N} / \mathrm{mm}^{2}\right) ;$ and $N$ is the axial load applied $(N)$. 
D. L. peña, V. Albero, C. Ibáñez, A. Hospitaler. Sectional model for the fire evaluation of reinforced concrete columns subjected to biaxial bending. Engineering Structures 2021; 247: 113094. https://doi.org/10.1016/j.engstruct.2021.113094

The bending capacity in each axis is determined by solving Eq. (2) and Eq. (3) by increasing gradually the value of the curvature of the cross-section in order to generate the $M$ $\kappa$ curve.

$$
\begin{aligned}
& \sum_{i=1}^{n} A_{i} \sigma_{i} z_{i}-M_{y}=0 \\
& \sum_{i=1}^{n} A_{i} \sigma_{i} y_{i}-M_{z}=0
\end{aligned}
$$

where $y_{i}$ and $z_{i}$ are, respectively, the $\mathrm{y}$-axis and z-axis positions of the centroid of cell $\mathrm{i}(\mathrm{mm})$; $M_{y}$ is the applied bending moment in y-axis (Nmm); and $M_{z}$ is the applied bending moment in $\mathrm{z}$-axis $(\mathrm{Nmm})$.

To obtain the interaction surface, the balance equations are solved for all the loading situations generated by rotating the neutral axis (angle $\alpha$ in Fig. 4a) and increasing the axial load from 0 up to the maximum value of the cross-sectional resistance $\left(N_{\max }\right)$. To illustrate this, Fig. $4 \mathrm{~b}$ is an example of an interaction surface generated by means of the numerical FM for a RC column with 3-sides exposed to the ISO834 standard temperature-time curve [25]. Specifically, to obtain the points of the failure surface it is necessary to get the M- $\kappa$ diagram for each point.

From this diagram, the maximum bending moment is traditionally obtained by means of the non-guided and computationally inefficient process of iterating the neutral axis position for a given curvature. For a given axial load and for each value of the curvature, the position of the neutral axis is varied and, by integrating the section, the cross-sectional balance equation is solved. The pair of values for the curvature and neutral axis which satisfies the balance equation will give the maximum axial force corresponding to the maximum bending moment. 
D. L. peña, V. Albero, C. Ibáñez, A. Hospitaler. Sectional model for the fire evaluation of reinforced concrete columns subjected to biaxial bending. Engineering Structures 2021; 247: 113094. https://doi.org/10.1016/j.engstruct.2021.113094

Considering the problem to be one of optimization allows a drastic reduction in the computational cost by programming a routine that finds the value of the neutral axis that minimizes the residual function (difference between axial load and internal axial force).

A combination of the fzero and fminsearch optimization algorithms available in Matlab [22] was used. The fzero function, which was originally developed by T.J. Dekker and later implemented by other authors [26], uses a combination of bisection, secant, and inverse quadratic interpolation methods. The fminsearch algorithm [27] conducts an unconstrained nonlinear optimization finding the minimum of a scalar function of several variables, starting at an initial estimate. In this problem, the input contains the unitary deformation at the origin and the curvature; and the output corresponds to the value of $N_{\max }$.

Applying this routine was particularly beneficial to calculate the value of $N_{\max }$ of the RC cross-section since its determination presents computational issues given the singularity of this point as the vertex of the failure surface. Employing this approach, it is possible to obtain this value in an efficient and precise manner.

\subsection{Thermal model validation}

The thermal model was validated with the experimental temperatures recorded in the tests carried out by Kodur et al.[28], Lie and Irwin [24] and Lie and Woollerton [29] where the columns were four-sided exposed to the ASTM-E119 standard temperature-time curve [30]. All the columns were normal strength reinforced concrete columns with siliceous aggregates. The details of the different specimens are summarised in Table 1. In total, the experimental data of 993 target points of RC cross-sections were employed for the validation of the thermal model. The results for the columns used in validation are shown in Fig. 5. The points lie mainly in the inner part of the $\pm 15 \%$ boundaries and those that exceed the limits are placed on the safe side. In this case, the precision of the thermal model increases for temperatures higher than $300^{\circ} \mathrm{C}$, 
D. L. peña, V. Albero, C. Ibáñez, A. Hospitaler. Sectional model for the fire evaluation of reinforced concrete columns subjected to biaxial bending. Engineering Structures 2021; 247: 113094. https://doi.org/10.1016/j.engstruct.2021.113094

as can be also seen in Table 2 where the mean error and standard deviation are shown. The error is calculated as $T_{\text {num }} / T_{\exp }$ so a value higher than 1 means that the thermal model is conservative.

As an example, for each cross-section the predicted temperature-time curves at the location of two thermocouples are plotted against the experimental points in Fig. 6. It is observed that the model is able to predict with good accuracy the evolution of the temperatures along time.

\subsection{Mechanical model validation}

Given the lack of experiments on columns subjected to biaxial bending in fire, the validation of the mechanical model is accomplished in this investigation by parts: (1) validation at ambient temperature for biaxial bending and (2) validation at high temperatures under uniaxial bending. For the ambient temperature validation, experimental results from the works presented by Bresler [2], Meek [31] and Ramamurthy [32] were considered. In total, data of 61 short columns subjected to biaxial bending were used whose details are shown in Table 3 . The good agreement between tests and predicted results (Mean=0.99, $\mathrm{SD}=0.17)$ is shown in Fig. 7, with all the points lying inside the $\pm 15 \%$ limits. A $3 \mathrm{D}$ error is defined in Eq. (4) as the quotient of the magnitude of the vector from the origin of coordinates to the experimental failure point (N, $M_{y}, M_{z}$ ) divided by the magnitude of the vector from the origin of coordinates to the predicted failure point at the numerical interaction surface (see Fig. 4b). The latter is given by the intersection with the interaction surface.

$$
\xi_{3 D}=\frac{\left\|(0,0,0)-\left(N, M_{y}, M_{z}\right)_{\exp }\right\|_{\vec{n}}}{\left\|(0,0,0)-\left(N, M_{y}, M_{z}\right)_{\text {fiber }}\right\|_{\vec{n}}}
$$

In Fig. $7 \mathrm{~b}$ the error in the prediction is plotted for all the columns. Only a few of the columns show a variability higher than one standard deviation but still lying on the safe side. 
D. L. peña, V. Albero, C. Ibáñez, A. Hospitaler. Sectional model for the fire evaluation of reinforced concrete columns subjected to biaxial bending. Engineering Structures 2021; 247: 113094. https://doi.org/10.1016/j.engstruct.2021.113094

For the validation at high temperatures under uniaxial bending, the FM predictions were contrasted with those given by the model presented by Law and Gillie [9]. The specimen taken as reference $(300 x 500 \mathrm{~mm}, 6 \phi 20)$ is a ISO834 [25] 3-sides exposed column. In Fig. 8 can be seen that the predictions given by both models are identical. Therefore, the predicted crosssectional capacity of the FM for uniaxial bending under fire is contrasted and proven to be satisfactory.

\section{PARAMETRIC STUDY}

\subsection{Study description}

Once the numerical FM was validated, it was used for conducting a parametric study. An extensive exploration of the biaxial bending behaviour of RC columns exposed to the ISO834 standard temperature-time curve was done in this parametric study. Specifically, six parameters were analysed (see Table 4) for columns with dimensions $(b x h)$ ranging from 30x30 to 60x60 $\mathrm{cm}$. The set of parameters studied includes the aspect ratio $(b / h)$ to take into account both square and rectangular cross-sections; the concrete compressive strength $\left(f_{c}\right)$; the reinforcement concrete cover $\left(u_{s}\right)$ measured from the external concrete surface to the centre of the reinforcing bar; the fire exposure time according to the standard ISO834 standard temperature-time curve; the reinforcement arrangement ratio $\left(A_{s, c} / A_{s}\right)$ to measure the relation between the reinforcing bars placed at the corners of the section $\left(A_{s, c}\right)$ and the total area of reinforcing bars $\left(A_{s}\right)$; and the reinforcement ratio $\left(\omega=A_{s} f_{y} / A_{c} f_{c}\right)$. For all the cases, siliceous aggregates are considered.

It is important to notice that ten different reinforcement arrangements for each crosssection were computed combining bars with diameters of 12,16 and $20 \mathrm{~mm}$ in order to cover a wide range of reinforcement ratios $(\omega)$. The range of the five parameters defined in Table 4 creates a configuration space of 3,600 different column cross-sections. Besides, in order to properly analyse the biaxial bending behaviour of each specimen, the FM described in section 
D. L. peña, V. Albero, C. Ibáñez, A. Hospitaler. Sectional model for the fire evaluation of reinforced concrete columns subjected to biaxial bending. Engineering Structures 2021; 247: 113094. https://doi.org/10.1016/j.engstruct.2021.113094

3 was computed for each configuration taking into account 8 rotation angles $(\beta)$ equally spaced in the range $0 \leq \beta \leq \pi / 2$. This short range can be used because all specimens were 4 -sided exposed to the fire action and, therefore, double symmetry- in geometry and boundary heating conditions- can be considered. Additionally, 29 axial load levels were applied ranging from the ultimate axial load in tension $\left(N_{u t}\right)$ to compression $\left(N_{u c}\right)$. The combination of all these parameters, rotation angles and applied loads results in a total amount of 835,200 computations executed by the FM. Thus, the results obtained during the extensive exploration of this configuration space constitute an extensive database for further analysis on the biaxial behaviour of RC columns in fire.

\subsection{Results from parametric analysis}

In the next sections, the influence of each parameter on the biaxial behaviour of RC columns in fire is analysed. To isolate the effect of one parameter at a time, the rest of the parameters considered in the study are not varied. For comparison purposes, a new variable is defined to quantify the biaxial bending behaviour of each RC column from a general point of view. In this work, this variable is defined as $V_{r}$, the volume enclosed by the $\left(N, M_{y}, M_{z}\right)$ 3D interaction surface (see Fig. 4b). This volume is computed using geometric algorithms from 3D points. The analysis done for each parameter is described hereafter:

\subsubsection{Concrete compressive strength $\left(f_{c}\right)$}

The case selected for this first analysis is a $30 \times 30 \mathrm{~cm}$ column with 12 reinforcing bars of $16 \mathrm{~mm}$ of diameter $\left(f_{y}=500 \mathrm{MPa}\right)$ and a concrete cover of $\mathrm{us}_{\mathrm{s}}=35 \mathrm{~mm}$. The interaction surfaces obtained for this cross-section using a concrete compressive strength equal to 30 and $50 \mathrm{MPa}$ for room temperature and after 120 minutes of standard fire exposure are shown in Fig. 9a.

The ratios between the volumes enclosed by interaction surfaces are: 
D. L. peña, V. Albero, C. Ibáñez, A. Hospitaler. Sectional model for the fire evaluation of reinforced concrete columns subjected to biaxial bending. Engineering Structures 2021; 247: 113094. https://doi.org/10.1016/j.engstruct.2021.113094

$$
\begin{aligned}
& \frac{V_{r(\text { Room })}\left(f_{c}=50 \mathrm{MPa}\right)}{V_{r(\text { Room })}\left(f_{c}=30 \mathrm{MPa}\right)}=2.32 \\
& \frac{V_{r(R 120)}\left(f_{c}=50 \mathrm{MPa}\right)}{V_{r(R 120)}\left(f_{c}=30 \mathrm{MPa}\right)}=2.39
\end{aligned}
$$

These values show that an increment in the concrete compressive strength leads to an important improvement of the biaxial bending behaviour both at ambient and high temperature, which can be measured as an increase of approximately $230 \%$ in the volume enclosed by the interaction surface. However, it is important to notice that this increment barely changes with the time of fire exposure. This finding may indicate that the benefit obtained when increasing the concrete grade is not significantly better at elevated temperatures when compared to the benefit obtained at ambient temperature.

\subsubsection{Reinforcement concrete cover $\left(u_{s}\right)$}

To illustrate the influence of the reinforcement concrete cover, the case of a $30 \mathrm{x} 40 \mathrm{~cm}$ column cross-section with concrete $f_{c}=40 \mathrm{MPa}$ and a reinforcement of 4 bars of $20 \mathrm{~mm}$ diameter in corners plus 10 bars of $10 \mathrm{~mm}$ diameter along column sides is selected. All reinforcing bars were of $f_{y}=500 \mathrm{MPa}$ steel grade. In this case, the variation of $u_{s}$ was studied for values of 25 and $55 \mathrm{~mm}$. The interaction volume ratios (see Fig. $9 \mathrm{~b}$ ) at room temperature and after 180 minutes of fire exposure are:

$$
\begin{aligned}
& \frac{V_{r(\text { Room })}\left(u_{s}=55 \mathrm{~mm}\right)}{V_{r(\text { Room })}\left(u_{s}=25 \mathrm{~mm}\right)}=0.78 \\
& \frac{V_{r(R 180)}\left(u_{s}=55 \mathrm{~mm}\right)}{V_{r(R 180)}\left(u_{s}=25 \mathrm{~mm}\right)}=4.28
\end{aligned}
$$

The ratios show a significant influence of the concrete cover. Firstly, it should be noticed that at room temperature the increase in the concrete cover worsens the bending behaviour due 
D. L. peña, V. Albero, C. Ibáñez, A. Hospitaler. Sectional model for the fire evaluation of reinforced concrete columns subjected to biaxial bending. Engineering Structures 2021; 247: 113094. https://doi.org/10.1016/j.engstruct.2021.113094

to the lower effective depth of the RC cross-section. In turn, at elevated temperatures an increase in the concrete cover produces an additional fire protection for the reinforcing bars. This is a well-studied behaviour that permits an important improvement in the fire behaviour of RC elements. Specifically, in this case the volume enclosed by the interaction surface for the specimen with $55 \mathrm{~mm}$ concrete cover is more than 4 times the one for $25 \mathrm{~mm}$. Indeed, it should be highlighted that most of the simplified methods for the assessment of these elements in fire are based on this parameter.

\subsubsection{Reinforcement ratio ( $\omega)$}

The next parameter studied is the reinforcement ratio. In this case a $30 \times 30 \mathrm{~cm}$ column cross-section is used but including 4 bars of $12 \mathrm{~mm}$ diameter $(\omega=0.08)$ or 4 bars of $20 \mathrm{~mm}$ diameter $(\omega=0.23)$ (all with $f_{y}=500 \mathrm{MPa}$ ) The concrete compressive strength for these columns was $f_{c}=30 \mathrm{MPa}$ and all reinforcing bars were placed with a concrete cover of $45 \mathrm{~mm}$. The volume enclosed ratio at room temperature and after 90 minutes of fire exposure (see in Fig. 9c) are:

$$
\begin{aligned}
& \frac{V_{r(\text { Room })}(\omega=0.23)}{V_{r(\text { Room })}(\omega=0.08)}=2.12 \\
& \frac{V_{r(R 90)}(\omega=0.23)}{V_{r(R 90)}(\omega=0.08)}=2.25
\end{aligned}
$$

It can be observed that for both situations, at room temperature and in fire, an increase in the reinforcement ratio enlarges the $V_{r}$. It should be noticed that the increment produced is approximately the same in both cases, which was also observed for the concrete compressive strength in section 4.2.1. 
D. L. peña, V. Albero, C. Ibáñez, A. Hospitaler. Sectional model for the fire evaluation of reinforced concrete columns subjected to biaxial bending. Engineering Structures 2021; 247: 113094. https://doi.org/10.1016/j.engstruct.2021.113094

\subsubsection{Reinforcement arrangement ratio $\left(A_{s, c} / A_{s}\right)$}

The last parameter studied here is the reinforcement arrangement ratio. The number of works found in the literature where the influence of this parameter is assessed is scarce and, as pointed out by Buch and Sharma [17], more works are needed where the fire resistance of eccentrically loaded RC columns is analysed considering the role of different reinforcement arrangements. This parameter is defined as the ratio between the reinforcement area placed at the corners and the total reinforcement area $\left(A_{s, c} / A_{s}\right)$. A value of $A_{s, c} / A_{s}=1$ means that all reinforcing bars are placed at the corners. The importance behind the study of this parameter in fire resides in the fact that reinforcing bars placed in corners are exposed to an increased heating -heated in two directions-, more intense than the heating of the bars placed along column sides -heated in one direction-.

Two columns with a cross-section of $30 \times 30 \mathrm{~cm}, f_{c}=30 \mathrm{MPa}$ and concrete cover $u_{s}=35 \mathrm{~mm}$ were selected. Both columns have approximately the same reinforcement ratio $\omega \approx 0.16$ but with a different arrangement. The first specimen has 4 bars of $16 \mathrm{~mm}$ diameter placed in corners $\left(A_{s, c} / A_{s}=1.0\right)$ while the second one has 8 bars of $12 \mathrm{~mm}$ diameter: 4 placed at the corners and 4 along the cross-section sides $\left(A_{s, c} / A_{s}=0.5\right)$.

The ratio of $V_{r}$ at room temperature and after 120 minutes of fire exposure (Fig. 9d) are:

$$
\begin{aligned}
& \frac{V_{r(\text { Room })}\left(A_{s, c} / A_{s}=0.5\right)}{V_{r(\text { Room })}\left(A_{s, c} / A_{s}=1.0\right)}=0.98 \\
& \frac{V_{r(R 120)}\left(A_{s, c} / A_{s}=0.5\right)}{V_{r(R 120)}\left(A_{s, c} / A_{s}=1.0\right)}=1.57
\end{aligned}
$$

The values obtained here are of high interest because, while the change on the reinforcement arrangement has no significant effect at room temperature $(\approx 1.0)$, the value in fire shows an important improvement $(\approx 57 \%)$. In Fig. 10 the curves given by the intersection 
D. L. peña, V. Albero, C. Ibáñez, A. Hospitaler. Sectional model for the fire evaluation of reinforced concrete columns subjected to biaxial bending. Engineering Structures 2021; 247: 113094. https://doi.org/10.1016/j.engstruct.2021.113094

of an horizontal plane (at $\mathrm{N}=1000 \mathrm{kN}$ level) with the $3 \mathrm{D}$ interaction surfaces at different fire exposure times are shown. The biaxial behaviour of both specimens is very similar but, after 60,90 or 120 minutes of standard fire exposure, the biaxial failure curve is always higher for the 0.5 reinforcement arrangement ratio specimen (red line). This implies that it is possible to find a reinforcement arrangement that improves the response in case of fire. This arrangement can be designed by reducing the number of bars placed at the corners, where they are highly exposed to fire, moving them to the cross-section sides. Note that the change in the reinforcement arrangement does not cause any decrement in the biaxial bending behaviour at room temperature, which makes it especially interesting.

\section{SIMPLIFIED DESIGN MODEL}

Some analytical expressions are available in the literature related to $\mathrm{M}-\mathrm{N}$ interaction diagrams of RC columns in fire [11][12]. These works mainly focus on $\mathrm{M}-\mathrm{N}$ interaction curves but do not take into account the biaxial bending behaviour and, sometimes, are based on complicated expressions difficult to be used in daily practice.

Therefore, the aim of this paper is the development of an analytical expression to build the $\mathrm{N}-\mathrm{M}_{\mathrm{y}}-\mathrm{M}_{\mathrm{z}} 3 \mathrm{D}$ failure interaction surface for the fire assessment of RC columns in practice. The development of this simplified model (SM) is based on the database described in previous sections and also combines the $\mathrm{M}-\mathrm{N}$ interaction curves with the $\mathrm{M}_{\mathrm{y}}-\mathrm{M}_{\mathrm{z}}$ Bresler's equation, already applied in [14] for RC columns in fire.

\subsection{Description}

The development of this expression for the $\mathrm{N}-\mathrm{M}_{\mathrm{y}}-\mathrm{M}_{z}$ 3D failure interaction surface definition is based on the one proposed by Bonet et al. [6] for the biaxial response of RC 
D. L. peña, V. Albero, C. Ibáñez, A. Hospitaler. Sectional model for the fire evaluation of reinforced concrete columns subjected to biaxial bending. Engineering Structures 2021; 247: 113094. https://doi.org/10.1016/j.engstruct.2021.113094

columns at room temperature. This surface can be built using a generatrix and a directrix, see Fig. 11. In particular, for the generatrix two branches can be defined:

- Descending branch:

$$
\left(\frac{N_{u c}-N}{N_{u c}-N_{d 2}}\right)^{\xi}-\left(\frac{M}{M_{d 2}}\right)=0 \quad N_{d 2} \leq N \leq N_{u c}
$$

- Ascending branch:

$$
\left(\frac{N_{u t}-N}{N_{u t}-N_{d 2}}\right)^{\tau}-\left(\frac{M}{M_{d 2}}\right)=0 \quad N_{u t} \leq N \leq N_{d 2}
$$

where $\xi$ and $\tau$ are the generatrix shape coefficients; $N_{u c}$ and $N_{u t}$ are the ultimate axial force in compression and tension respectively; $N_{d 2}$ is the axial force at maximum bending moment resistance; and $M_{d 2}$ is the maximum bending moment resistance at direction $\beta$.

In turn, in order to compute $M_{d 2}$ for the required direction $\beta$, the Bresler's equation can be used as the directrix:

$$
\left(\frac{M_{d 2} \cos \beta}{M_{d 2, z}}\right)^{\eta}+\left(\frac{M_{d 2} \sin \beta}{M_{d 2, y}}\right)^{\eta}=1
$$

These three equations define the shape of the interaction failure surface (Fig. 11) and are based on four main points that should be obtained previously from the cross-section equilibrium equations. These four points are $N_{u c}$ and $N_{u t}$, ultimate axial forces in compression and tension; and $M_{d 2, y}$ and $M_{d 2, z}$, maximum bending moments in both principal directions.

Once the directrix and generatrix are defined, the following step consists of obtaining the shape coefficients $\xi$ and $\tau$, which can be numerically computed using the database and the following expressions shown in Eq. (16) and (17): 
D. L. peña, V. Albero, C. Ibáñez, A. Hospitaler. Sectional model for the fire evaluation of reinforced concrete columns subjected to biaxial bending. Engineering Structures 2021; 247: 113094. https://doi.org/10.1016/j.engstruct.2021.113094

$$
\begin{aligned}
& \xi=\ln \left(\frac{M}{M_{d 2}}\right) / \ln \left(\frac{N_{u c}-N}{N_{u c}-N_{d 2}}\right) \\
& \tau=\ln \left(\frac{M}{M_{d 2}}\right) / \ln \left(\frac{N_{u t}-N}{N_{u t}-N_{d 2}}\right)
\end{aligned}
$$

Through the expressions above, $\xi$ and $\tau$ were calculated for the 835,200 computations detailed in the parametric study. Next, a regression model was used to fit them in basic equations as shown in Eq. (18) and (19):

$$
\begin{aligned}
\xi & =0.95-0.2 n_{c}-0.3 n_{c}^{2} \\
\tau & =0.9-0.6 n_{t}
\end{aligned}
$$

where $n_{c}$ and $n_{t}$ are the nondimensional axial forces in compression and tension respectively given by:

$$
\begin{aligned}
& n_{c}=\frac{N_{u c}-N}{N_{u c}-N_{d 2}} \\
& n_{t}=\frac{N_{u t}-N}{N_{u t}-N_{d 2}}
\end{aligned}
$$

The simplistic approach of the previous regression models for $\xi$ and $\tau$ was chosen due to the high data dispersion obtained, see Fig. 12 and Fig. 13. Thus, basic conservative equations were selected with approximately only $2.4 \%$ of unsafe predictions lying below the $15 \%$ error border.

Finally, the Bresler's exponent $\eta$ for Eq. (15) was computed following the same procedure as for the previous generatrix coefficients. Due to statistic criteria, the four different equations summarised in Table 5 were proposed in terms of the standard fire exposure and the reinforcement arrangement ratio at the corners of the cross-section $\left(A_{s, c} / A_{s}\right)$. These equations depend on parameters like the column aspect ratio $(b / h)$; the reinforcing bars concrete cover 
D. L. peña, V. Albero, C. Ibáñez, A. Hospitaler. Sectional model for the fire evaluation of reinforced concrete columns subjected to biaxial bending. Engineering Structures 2021; 247: 113094. https://doi.org/10.1016/j.engstruct.2021.113094

$\left(u_{s}\right)$, the reinforcement ratio $(\omega)$ and the fire exposure time $(t)$ in hours. Fig. 15 shows the accurate fitting of the proposed SM versus the FM results.

In Fig. 14 a flowchart summarising the SM and the steps that need to be followed is shown.

\subsection{Verification}

The predictions given by the SM for the assessment of RC columns under biaxial bending in fire were finally validated against the results produced by the numerical simulations carried out by the FM (described in section 3). In total, 720 columns were selected from the parametric analysis to be used as a verification set. These specimens were chosen well-spaced along the parameters range.

To measure the error of the SM predictions with respect to the numerical model results, the volume $V_{r}$ enclosed by the 3D interaction surface was computed in each case. The error is defined as the relation between both volumes as $V_{r, f i b e r} / V_{r \text {,model. }}$ This ratio can be observed in Fig. 16 with a mean value of 0.84 , conservative, and a standard deviation of 0.02 , which denote a very good fitting.

Although the comparison of the $V_{r}$ gives a measurement of the conservativeness of the simplified method, an alternative definition for the error may be necessary to take into account the comparison of the shape of the volumes for the whole axial load range (and not only the quantification of the volume itself). Thus, the relative root-mean square error (RRMSE) was computed according to Eq. (22) for all the numerical points along the interaction surface, see Fig. 17a. This error was obtained for the 720 columns considered in the verification set.

$$
R R M S E=\frac{\sqrt{\frac{1}{n} \sum\left(\|x\|_{\text {fiber }}-\|x\|_{\text {mod el }}\right)^{2}}}{\frac{1}{n} \sum\|x\|_{\text {fiber }}}
$$


D. L. peña, V. Albero, C. Ibáñez, A. Hospitaler. Sectional model for the fire evaluation of reinforced concrete columns subjected to biaxial bending. Engineering Structures 2021; 247: 113094. https://doi.org/10.1016/j.engstruct.2021.113094

The RRMSE histogram (Fig. 17b) plot shows a mean error value of 5\% and a maximum deviation of $15 \%$, which confirms the accurate fitting of the SM. Additionally, it is worthy to notice that the distribution of the error for different fire exposure times (Fig. 17c) shows a very low error and deviation for fire exposures lower than 120 minutes, which are the most common in practice.

\section{WORKED EXAMPLE}

To illustrate the application of the proposed SM, an example of a real column is developed in this section. A column with dimensions $45 \times 45 \mathrm{~cm}$ with a reinforcement of $4 \phi 20+4 \phi 16$ is analysed, see Fig. 18a. The concrete compression strength is $f_{c}=25 \mathrm{MPa}$ while the steel grade is $f_{y}=400 \mathrm{MPa}$. The concrete cover, measured to the bar centre, is $\mathrm{u}_{\mathrm{s}}=46 \mathrm{~mm}$.

The data used in this worked example was obtained from a real structural project carried out in the city of Valencia, Spain. This project was developed for an office building, $20 \mathrm{~m}$ tall, whose structure consists of a reinforced concrete framework which supports a bidirectional floor system that results in biaxial bending in the columns. The column analysed was placed in the fifth floor and presents the loads showed in Table 6.

It should be noticed that the Spanish national standard for buildings requires 90 minutes (R90) of standard fire resistance for buildings with an evacuation level lower than $28 \mathrm{~m}$. Therefore, the objective here is to define the failure interaction curve for this column after 90min of standard fire exposure and then assess whether the point defined by the three loads lies inside, which will imply the good performance of the column in terms of fire safety.

Turning to the applied loads, the values from Table 6 should be firstly combined using, for an accidental design situation and following the Spanish building standard, the frequent combination factor for variable live loads $\left(\psi_{1}=0.7\right)$. This combination can be done following 
D. L. peña, V. Albero, C. Ibáñez, A. Hospitaler. Sectional model for the fire evaluation of reinforced concrete columns subjected to biaxial bending. Engineering Structures 2021; 247: 113094. https://doi.org/10.1016/j.engstruct.2021.113094

EN 1991-1-2 [23] provisions. Thus, the total applied loads on the columns are $\mathrm{N}=1196 \mathrm{kN}, \mathrm{M}_{\mathrm{y}}$ $=-29.7 \mathrm{kNm}$, and $\mathrm{M}_{\mathrm{z}}=26.5 \mathrm{kNm}$.

The total bending moment and its direction can be obtained from the applied bending moments in principal directions:

$$
\begin{aligned}
& M_{\text {tot }}=\sqrt{M_{y}{ }^{2}+M_{z}^{2}}=39.8 \mathrm{kNm} \\
& \cos \beta=\frac{M_{z}}{M_{t o t}}=0.666
\end{aligned}
$$

Secondly, to build the interaction surface, the four pivot points described in section 5.1 should be computed using the equilibrium equations at elevated temperature after $90 \mathrm{~min}$ of fire exposure. These are $N_{u t}=-662 \mathrm{kN} ; N_{u c}=4300 \mathrm{kN} ; M_{d 2, z}=M_{d 2, y}=250.7 \mathrm{kNm} ; N_{d 2}=1520 \mathrm{kN}$.

Eq. (15) should be used to compute $M_{d 2}$ in the required direction using Bresler's exponent from Table 5. In this case, the reinforcement arrangement ratio is lower than $1.0\left(\mathrm{~A}_{\mathrm{s}, \mathrm{c}} / \mathrm{A}_{\mathrm{s}}<1\right)$ and the exposure time is higher than zero $(t>0)$, then $\eta=1.70$.

Therefore, $M d 2$ can be solved from Eq. (15) as follows:

$$
\left(\frac{M_{d 2} \cos \beta}{250.7}\right)^{1.7}+\left(\frac{M_{d 2} \sin \beta}{250.7}\right)^{1.7}=1 \rightarrow M_{d 2}=\frac{250.7}{\left[(\cos \beta)^{1.7}+(\sin \beta)^{1.7}\right]^{1 / 1.7}}=235.9 \mathrm{kNm}
$$

The generatrix is finally computed knowing that the total applied axial force belongs to the ascending branch range, see Eq. (14):

$$
N_{u t} \leq N \leq N_{d 2} \rightarrow-662 k N<1196 k N<1520 k N
$$

The exponent $\tau$ for this ascending branch is obtained from Eq. (19):

$$
\tau=0.9-0.6\left(\frac{N_{u t}-N}{N_{u t}-N_{d 2}}\right)=0.9-0.6\left(\frac{-662-1196}{-662-1520}\right)=0.39
$$

and $\mathrm{M}$ can be obtained from Eq. (14): 
D. L. peña, V. Albero, C. Ibáñez, A. Hospitaler. Sectional model for the fire evaluation of reinforced concrete columns subjected to biaxial bending. Engineering Structures 2021; 247: 113094. https://doi.org/10.1016/j.engstruct.2021.113094

$$
\left(\frac{N_{u t}-N}{N_{u t}-N_{d 2}}\right)^{\tau}-\left(\frac{M}{M_{d 2}}\right)=0 \rightarrow M=235.9\left(\frac{-662-1196}{-662-1520}\right)^{0.39}=221.57 \mathrm{kNm}
$$

Since $M>M_{\text {tot }}(221.57 \mathrm{kNm}>39.8 \mathrm{kNm})$ it can be confirmed that the applied load point lies inside the failure load surface (see Fig. 18b), which is a conservative result.

\section{CONCLUDING REMARKS}

In this paper a SM to assess the cross-sectional capacity of RC columns subjected to biaxial bending and fire was presented. First, a sequentially coupled numerical FM was developed to obtain the cross-sectional interaction diagram, and validated against experimental and numerical data. Through a parametric study, the influence of the concrete compressive strength, the concrete cover, the reinforcement ratio and the reinforcement arrangement on the fire capacity was investigated. Finally, the SM based on the Bresler's equation was developed and validated. According to the work presented, the following conclusions can be drawn:

- There is a lack of experimental studies on the fire behaviour of RC columns subjected to combined axial load and biaxial bending. More tests in this line should be done for a better understanding and to permit a proper assessment of the current codes, the validation of numerical models and the proposal of new simplified models.

- Although some simplified models for the design of RC columns in fire can be found, are scarce those related to biaxial bending that can be used in daily practice.

- The numerical FM developed was successfully validated to reproduce the fire response of RC columns subjected to biaxial bending.

- An increment in the reinforcement concrete cover $\left(u_{s}\right)$ and a proper reinforcement arrangement $\left(A_{s, c} / A_{s}\right)$ are the most promising strategies to improve efficiently the biaxial bending behaviour of RC columns in fire. Contrarily, other parameters like the concrete 
D. L. peña, V. Albero, C. Ibáñez, A. Hospitaler. Sectional model for the fire evaluation of reinforced concrete columns subjected to biaxial bending. Engineering Structures 2021; 247: 113094. https://doi.org/10.1016/j.engstruct.2021.113094

compressive strength $\left(f_{c}\right)$ and the reinforcement ratio $(\omega)$ do not have a significant influence in the fire behaviour of these columns.

- A SM for the fire design of RC columns under biaxial loading was presented. The SM was successfully validated and proved to be of simple application for daily practice. 
D. L. peña, V. Albero, C. Ibáñez, A. Hospitaler. Sectional model for the fire evaluation of reinforced concrete columns subjected to biaxial bending. Engineering Structures 2021; 247: 113094. https://doi.org/10.1016/j.engstruct.2021.113094

\section{ACKNOWLEDGEMENTS}

The authors gratefully acknowledge the financial support given by the National Agency for Research and Development (ANID)/ Scholarship Program/ DOCTORADO BECAS CHILE/2018 - 72190104 for the first author's doctoral fellowship at Universitat Politècnica de València.

\section{REFERENCES}

[1] CEN. EN 1992-1-1, Eurocode 2: Design of concrete structures, Part 1.1: General rules and rules for buildings, Brussels, Belgium: Comité Européen de Normalisation; 2004.

[2] Bresler B. Design criteria for reinforced columns under axial load and biaxial bending, Journal of the American Concrete Institute. 1960; 57(11): 481-490.

[3] Hsu CTT. Analysis and Design of Square and Rectangular Columns by Equation of Failure Surface, ACI Structural Journal. 1988; 85(2): 167-179.

[4] Hong HP. Short reinforced concrete column capacity under biaxial and axial load, Canadian Journal of Civil Engineering. 2000; 27: 1173-1182.

[5] Wang W, Hong HP. Appraisal of Reciprocal Load Method for Reinforced Concrete Columns of Normal and High Strength Concrete, Journal of Structural Engineering. 2002; 128(11): 1480-1486.

[6] Bonet JL, Miguel PF, Fernández MA, Romero ML. Analytical approach to failure surfaces in reinforced concrete sections subjected to axial loads and biaxial bending, Journal of Structural Engineering. 2004; 130 (12): 2006-2015.

[7] Al-Ansari MS, Afzal MS. Simplified biaxial column interaction charts, Engineering Reports. 2019; 1(e12076): 1-15.

[8] Bamonte P, Gambarova PG, Meda A. Today's concretes exposed to fire-test results and sectional analysis, Structural Concrete, Journal of the fib. 2008; 9(1): 19-29.

[9] Law A, Gillie M. Interaction diagrams for ambient and heated concrete sections, Engineering Structures. 2010; 32(6): 1641-1649.

[10] Caldas RB, Sousa JBM, Fakury RH. Interaction diagrams for reinforced concrete sections subjected to fire, Engineering Structures 2010; 32: 2832-2838. 
D. L. peña, V. Albero, C. Ibáñez, A. Hospitaler. Sectional model for the fire evaluation of reinforced concrete columns subjected to biaxial bending. Engineering Structures 2021; 247: 113094. https://doi.org/10.1016/j.engstruct.2021.113094

[11] El-Fitiany SF, Youssef MA. Interaction diagrams for fire-exposed reinforced concrete sections, Engineering Structures. 2014; 70: 246-259.

[12] Pham DT, Buhan P, Florence C, Heck JV, Nguyen HH. Interaction diagrams of reinforced concrete sections in fire: A yield design approach, Engineering Structures. 2015; 90: 38-47.

[13] CEN. EN 1992-1-2, Eurocode 2: Design of concrete structures, Part 1.2: General rules - Structural fire design, Brussels, Belgium: Comité Européen de Normalisation; 2004.

[14] Wang L, Van Coile R, Caspeele R, Taerwe L. Simplified method for evaluating the biaxial capacity of rectangular reinforced concrete columns during fire, Materials and Structures. 2017, 50, p. 1-13.

[15] Tan KH, Nguyen TT. Experimental behaviour of restrained reinforced concrete columns subjected to equal biaxial bending at elevated temperatures, Engineering Structures. 2013; 56: 823-836.

[16] Kodur V, Raut N. A simplified approach for predicting fire resistance of reinforced concrete columns under biaxial bending, Engineering Structures. 2012; 41: 428-443.

[17] Buch SH, Sharma UK. Fire Resistance of Eccentrically Loaded Reinforced Concrete Columns, Fire technology. 2019; 55: 1517-1552,

[18] Dotreppe JC, Franssen JM, Bruls A, Baus R, Vandevelde P, Minne R, van Nieuwenburg D, Lambotte H. Experimental research on the determination of the main parameters affecting the behaviour of reinforced concrete columns under fire conditions, Magazine of Concrete Research. 1996; 49(179):117-127.

[19] Tan KH, Yao Y. Fire resistance of four- face heated reinforced concrete columns, Journal of Structural Engineering. 2003; 129(9): 1120-1229.

[20] Chen L, Liu, SW, Chan SL. Divergence-free algorithms for moment-thrust-curvature analysis of arbitrary sections, Steel and Composite Structures. 2017; 25(5): 557-569.

[21] Peña DL, Ibáñez C, Albero V, Espinós A, Hospitaler A, Romero ML. Influence of spalling on the biaxial bending resistance of reinforced concrete columns exposed to fire, 11th International Conference on Structures in Fire (SIF 2020). Online: University of Queensland, Australia. 2020; 204 - 211.

[22] MATLAB, 2020. Natick: The MathWorks Inc.

[23] CEN. EN 1991-1-2, Eurocode 1: Actions on structures, Part 1.2: General actions Actions on structures exposed to fire, Brussels, Belgium: Comité Européen de Normalisation; 2002. 
D. L. peña, V. Albero, C. Ibáñez, A. Hospitaler. Sectional model for the fire evaluation of reinforced concrete columns subjected to biaxial bending. Engineering Structures 2021; 247: 113094. https://doi.org/10.1016/j.engstruct.2021.113094

[24] Lie TT, Irwin RJ. Evaluation of the fire resistance of reinforced concrete columns with rectangular cross- sections. Internal Report 601, Institute for Research in Construction, National Research Council of Canada (NRCC), 1990, Ottawa, Canada.

[25] ISO (International Standards Organization). ISO 834: Fire resistance tests, elements of building construction. Switzerland: International Standards Organisation; 1980.

[26] Forsythe GE, Malcolm MA, Moler CB. Computer Methods for Mathematical Computations, Prentice-Hall, 1976.

[27] Lagarias JC, Reeds JA, Wright MH, Wright PE. Convergence Properties of the NelderMead Simplex Method in Low Dimensions. SIAM Journal of Optimization. 1998; 9(1): 112-147.

[28] Kodur V, Cheng F, Wang T, Latour J, Leroux P. Fire Resistance of High-Performance Concrete Columns. Internal Report 834, Institute for Research in Construction, National Research Council of Canada (NRCC), 2001, Ottawa, Canada.

[29] Lie TT, Woollerton JL. Fire Resistance of Reinforced Concrete Columns - Test Results. Internal Report, National Research Council Canada, Internal Report No 569, Institute for Research in Construction, National Research Council of Canada (NRCC), 1988, Ottawa, Canada.

[30] ASTM E119-20, Standard Test Methods for Fire Tests of Building Construction and Materials, ASTM International, West Conshohocken, PA, 2020.

[31] Meek J. Ultimate Strength of Columns with Biaxially Eccentric Loads, Journal ACI. 1963, 60: 1053-1064.

[32] Ramamurthy L, Investigation of the Ultimate Strength of Square and Rectangular Columns under Biaxially Eccentric Loads, Journal ACI. 1966. 13: 263-298. 
D. L. peña, V. Albero, C. Ibáñez, A. Hospitaler. Sectional model for the fire evaluation of reinforced concrete columns subjected to biaxial bending. Engineering Structures 2021; 247:

113094. https://doi.org/10.1016/j.engstruct.2021.113094
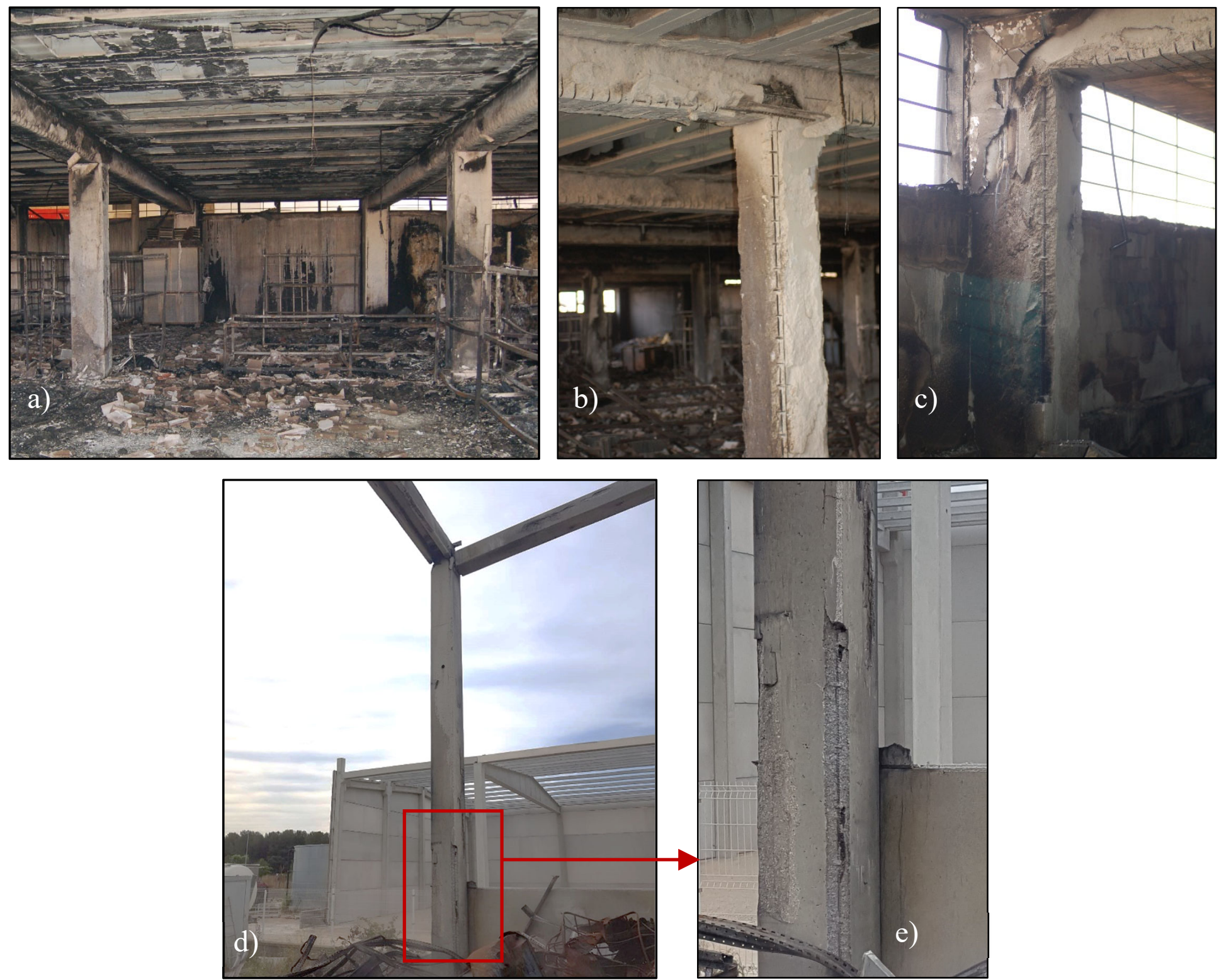

Fig. 1. a) RC industrial building after a fire; b) Column after a fire (corner spalling); c)

Lateral column after a fire; d) RC corner column at industrial building after a fire; e) Detail of spalling in RC corner column. 
D. L. peña, V. Albero, C. Ibáñez, A. Hospitaler. Sectional model for the fire evaluation of reinforced concrete columns subjected to biaxial bending. Engineering Structures 2021; 247: 113094. https://doi.org/10.1016/j.engstruct.2021.113094

Sequentially coupled thermal—stress analysis

\section{MECHANICAL MODEL}

Starting geometry (fiber mesh)

\section{THERMAL MODEL}

$\checkmark$

Mechanical properties for materials at elevated temperatures
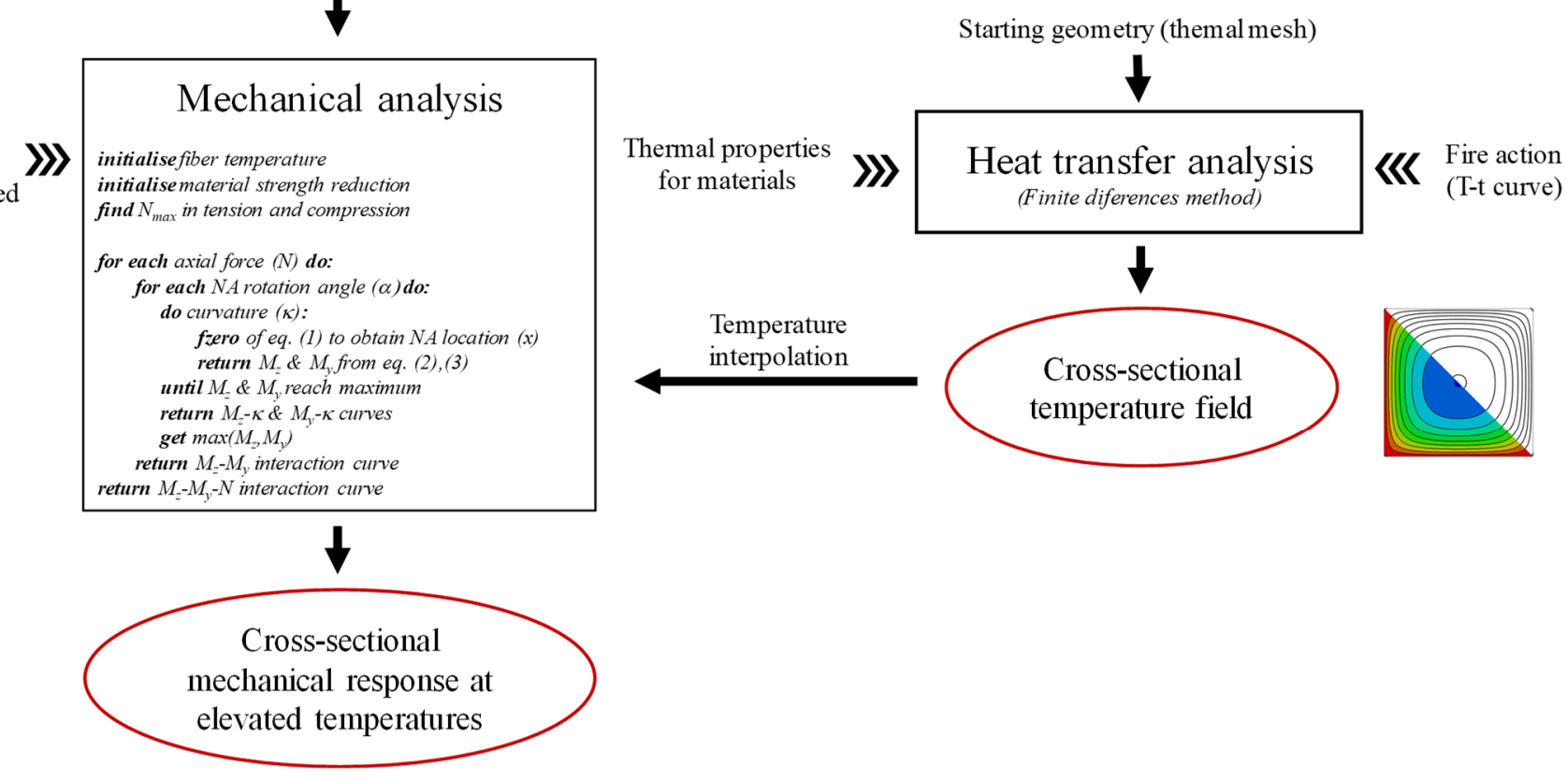

Fig. 2. Fiber numerical model flowchart 
D. L. peña, V. Albero, C. Ibáñez, A. Hospitaler. Sectional model for the fire evaluation of reinforced concrete columns subjected to biaxial bending. Engineering Structures 2021; 247: 113094. https://doi.org/10.1016/j.engstruct.2021.113094
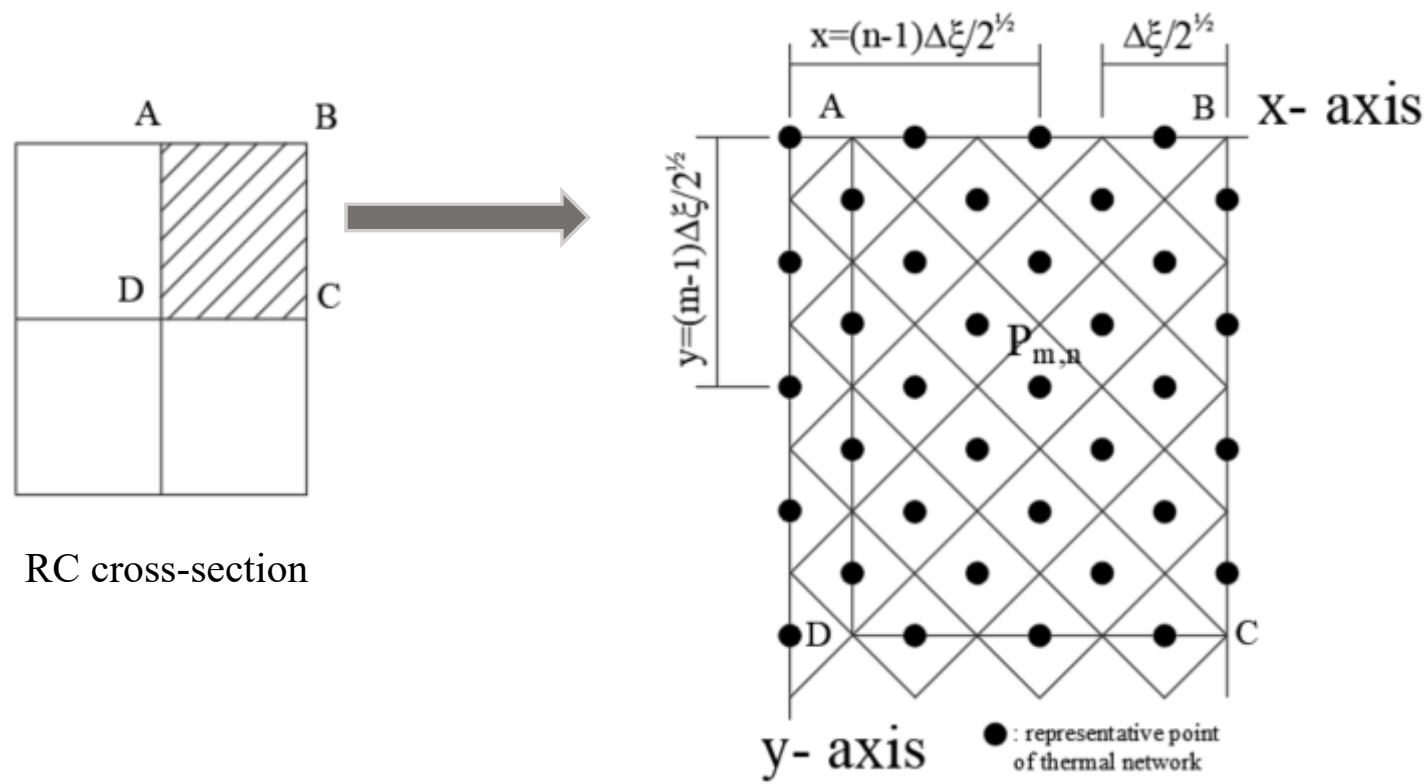

Fig. 3. Cross-section discretisation for the thermal analysis 
D. L. peña, V. Albero, C. Ibáñez, A. Hospitaler. Sectional model for the fire evaluation of reinforced concrete columns subjected to biaxial bending. Engineering Structures 2021; 247: 113094. https://doi.org/10.1016/j.engstruct.2021.113094

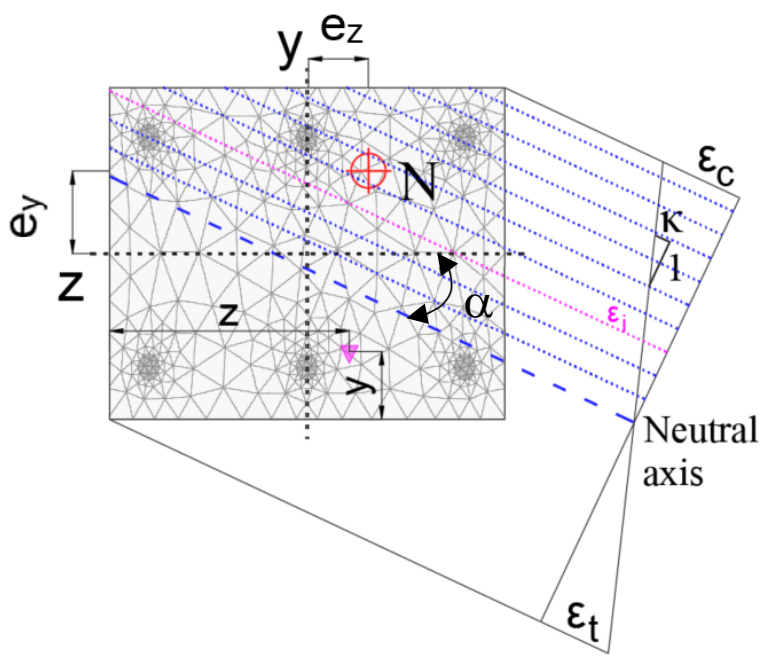

a)

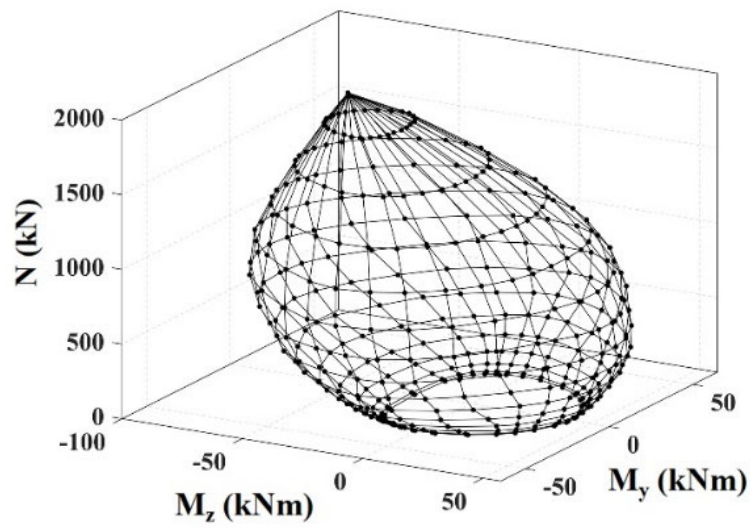

b)

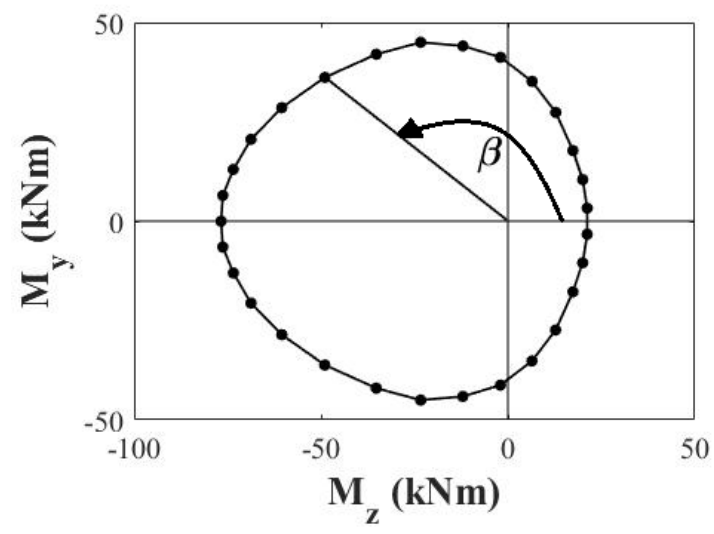

c)

Fig. 4. Fiber model a) Cross-section discretisation and strain distribution; b) 3D failure surface; c) Rotation angle 
D. L. peña, V. Albero, C. Ibáñez, A. Hospitaler. Sectional model for the fire evaluation of reinforced concrete columns subjected to biaxial bending. Engineering Structures 2021; 247: 113094. https://doi.org/10.1016/j.engstruct.2021.113094
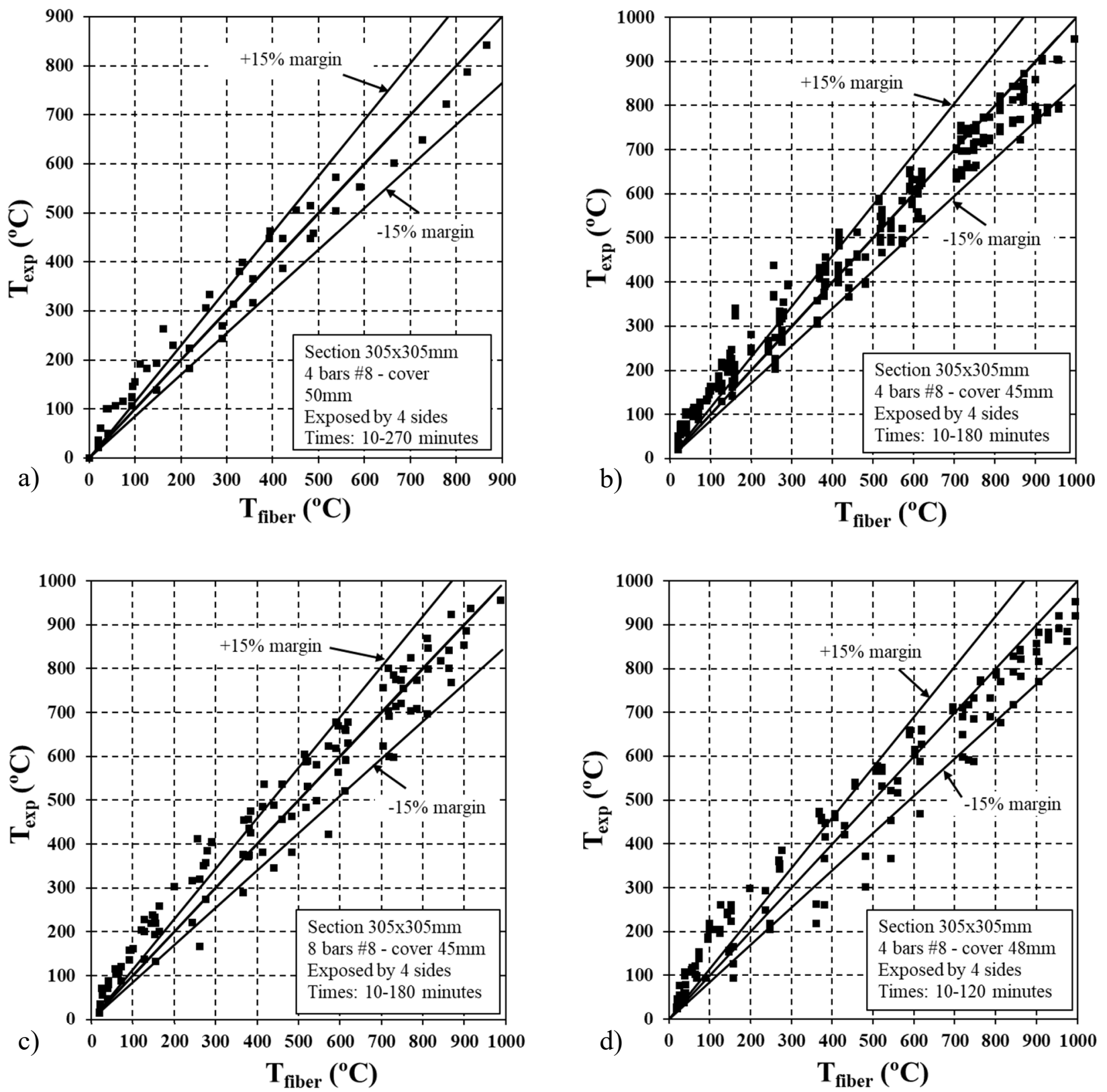

Fig. 5. Experimental vs. fiber model predictions: a) Series I TNC1 [28]; b) Col.1 [24]; c) Col. 2 [24]; d) Series I Col.1 [29] 
D. L. peña, V. Albero, C. Ibáñez, A. Hospitaler. Sectional model for the fire evaluation of reinforced concrete columns subjected to biaxial bending. Engineering Structures 2021; 247: 113094. https://doi.org/10.1016/j.engstruct.2021.113094
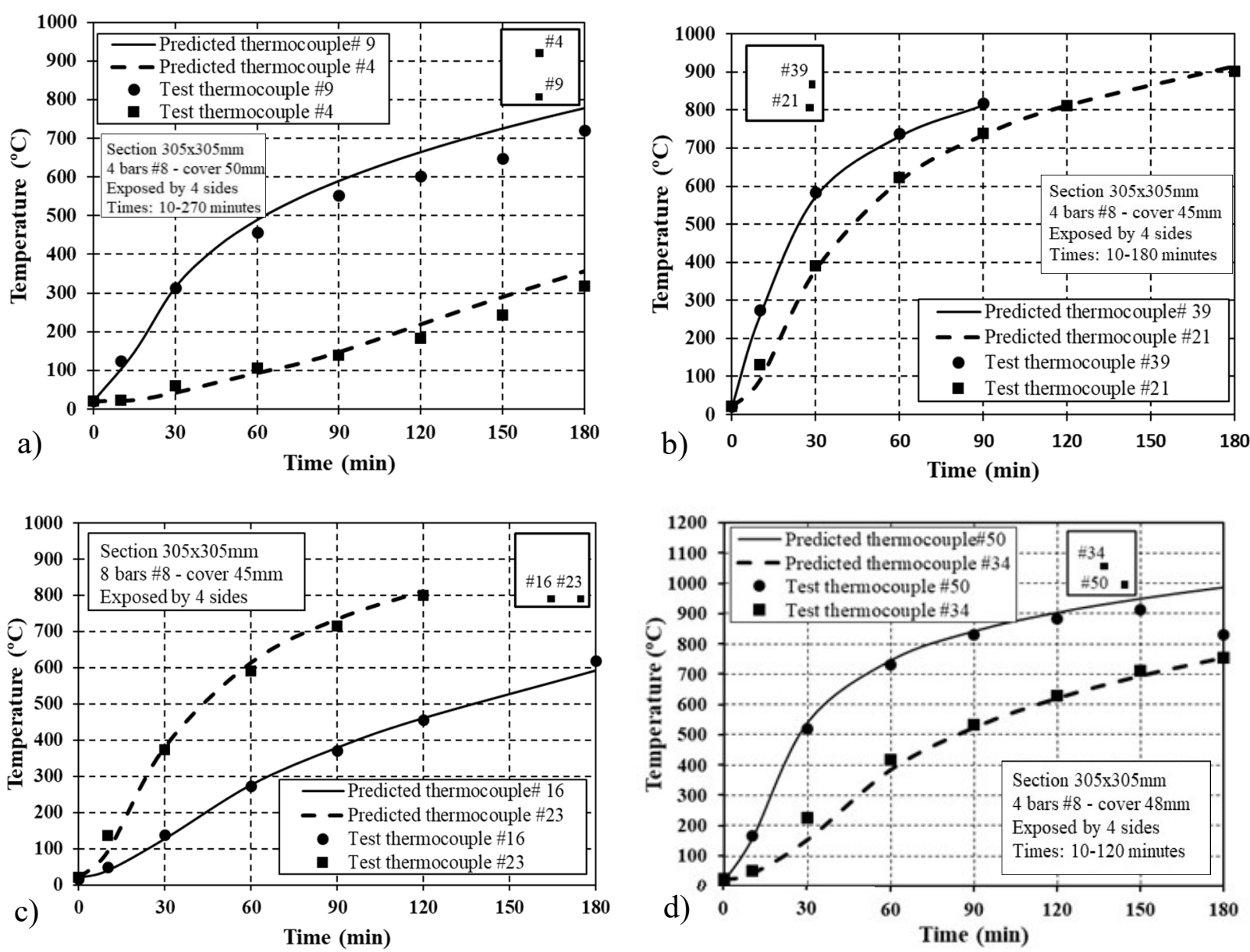

Fig. 6. Temperature-time curves: a) Series I TNC1 [28]; b) Col.1 [24]; c) Col. 2 [24]; d) Series I Col.1 [29] 
D. L. peña, V. Albero, C. Ibáñez, A. Hospitaler. Sectional model for the fire evaluation of reinforced concrete columns subjected to biaxial bending. Engineering Structures 2021; 247: 113094. https://doi.org/10.1016/j.engstruct.2021.113094

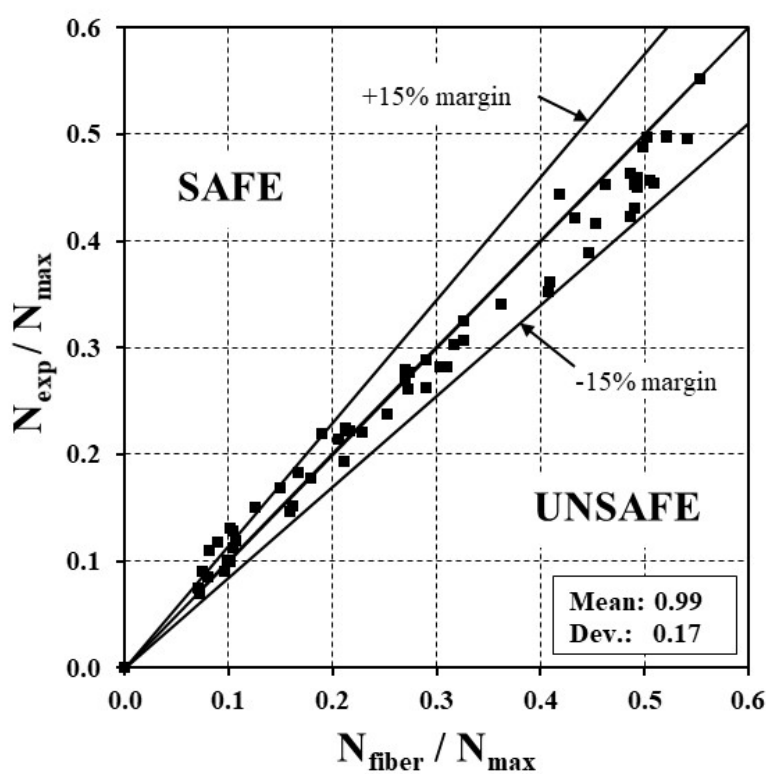

a)

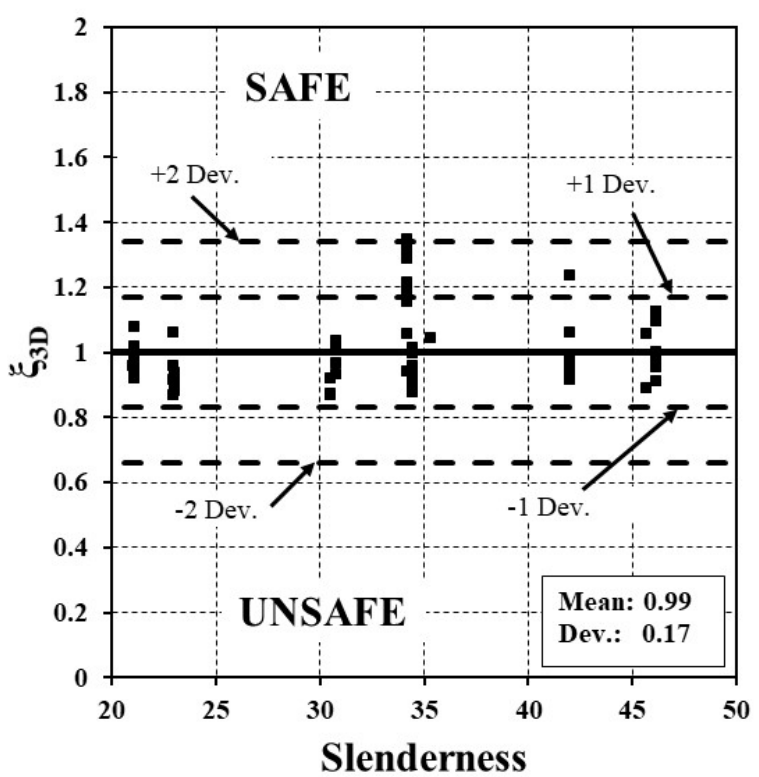

b)

Fig. 7. a) Experimental vs. fiber model predictions; b) Prediction error
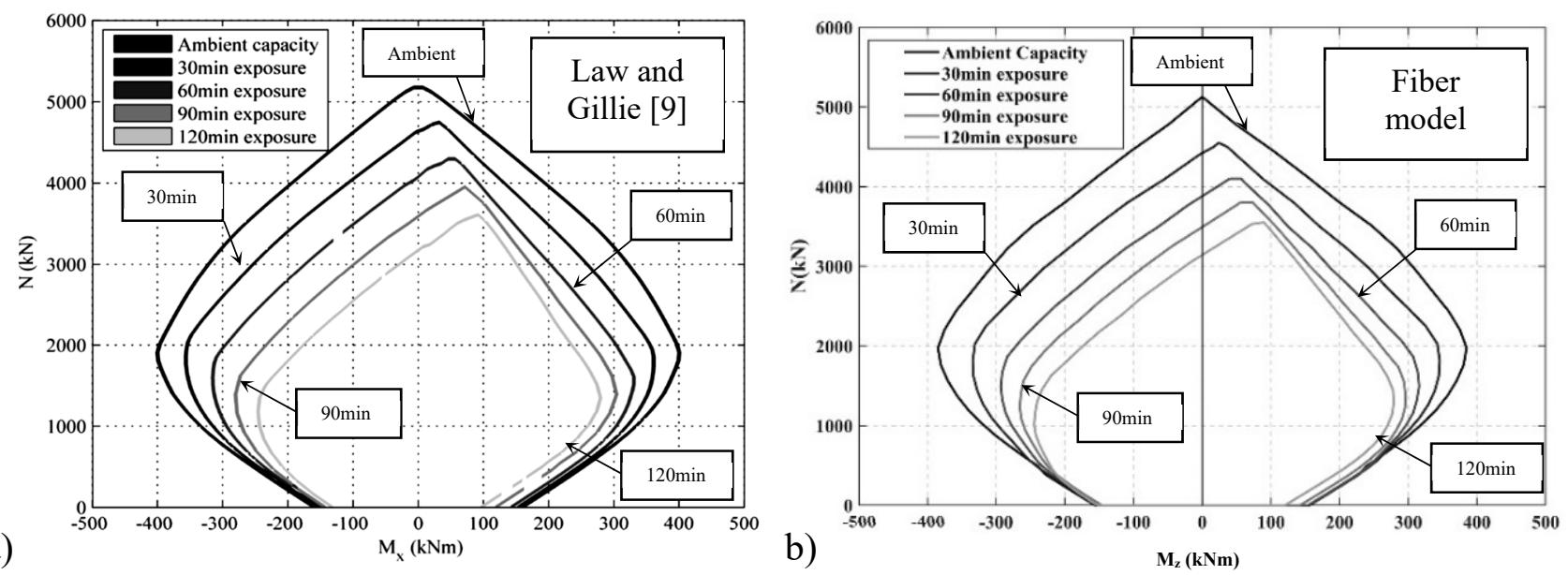

Fig. 8. Uniaxial interaction diagrams for different fire exposure times 
D. L. peña, V. Albero, C. Ibáñez, A. Hospitaler. Sectional model for the fire evaluation of reinforced concrete columns subjected to biaxial bending. Engineering Structures 2021; 247: 113094. https://doi.org/10.1016/j.engstruct.2021.113094

a)
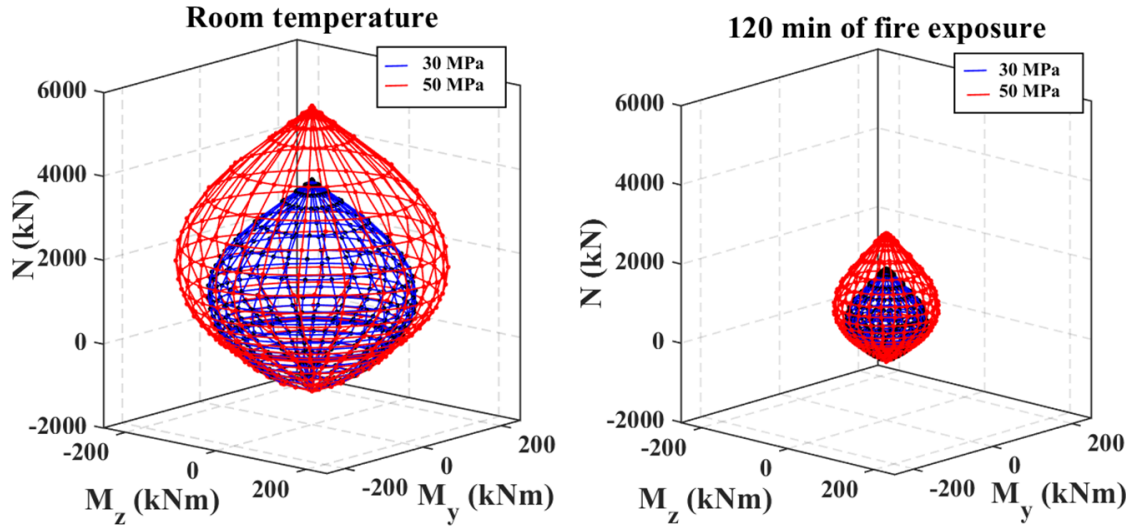

b)
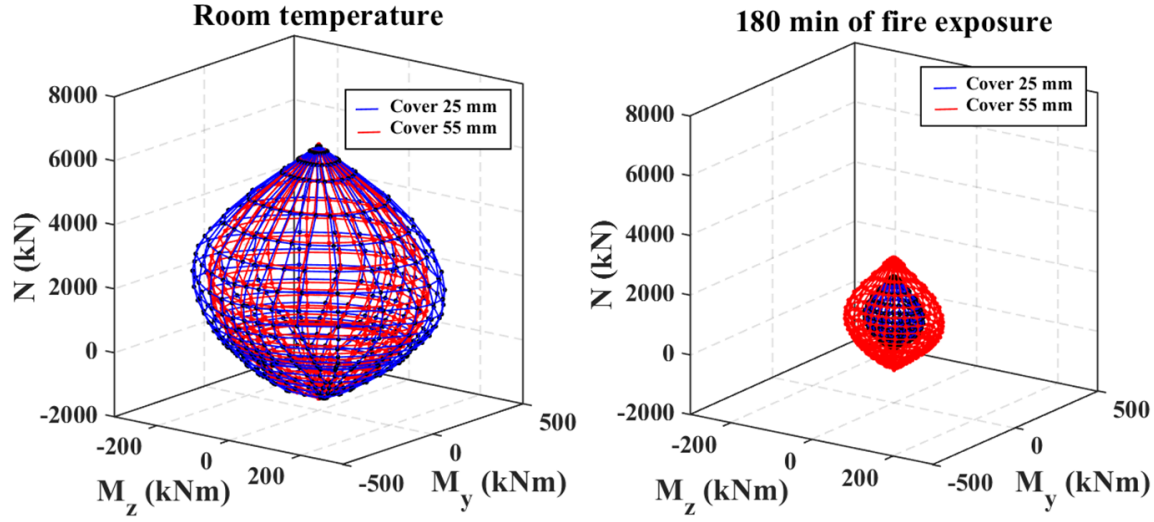

c)
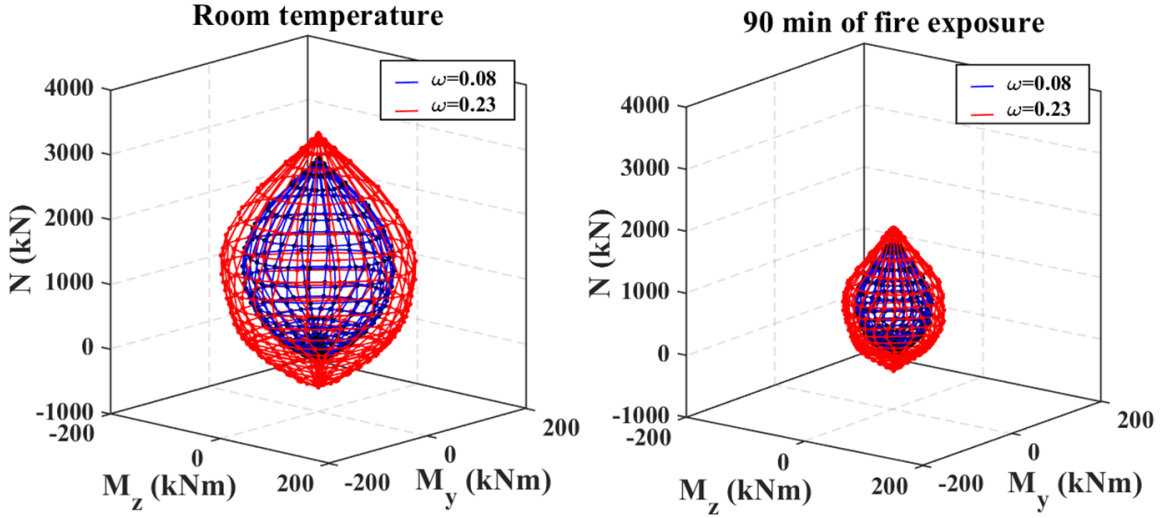

d)
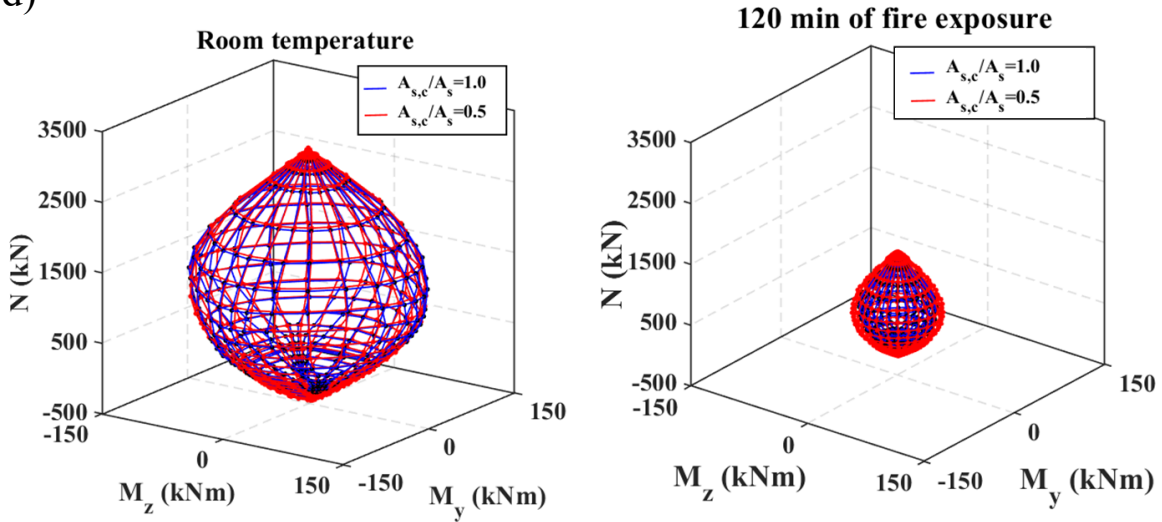
D. L. peña, V. Albero, C. Ibáñez, A. Hospitaler. Sectional model for the fire evaluation of reinforced concrete columns subjected to biaxial bending. Engineering Structures 2021; 247: 113094. https://doi.org/10.1016/j.engstruct.2021.113094

Fig. 9. Results from parametric study 
D. L. peña, V. Albero, C. Ibáñez, A. Hospitaler. Sectional model for the fire evaluation of reinforced concrete columns subjected to biaxial bending. Engineering Structures 2021; 247: 113094. https://doi.org/10.1016/j.engstruct.2021.113094

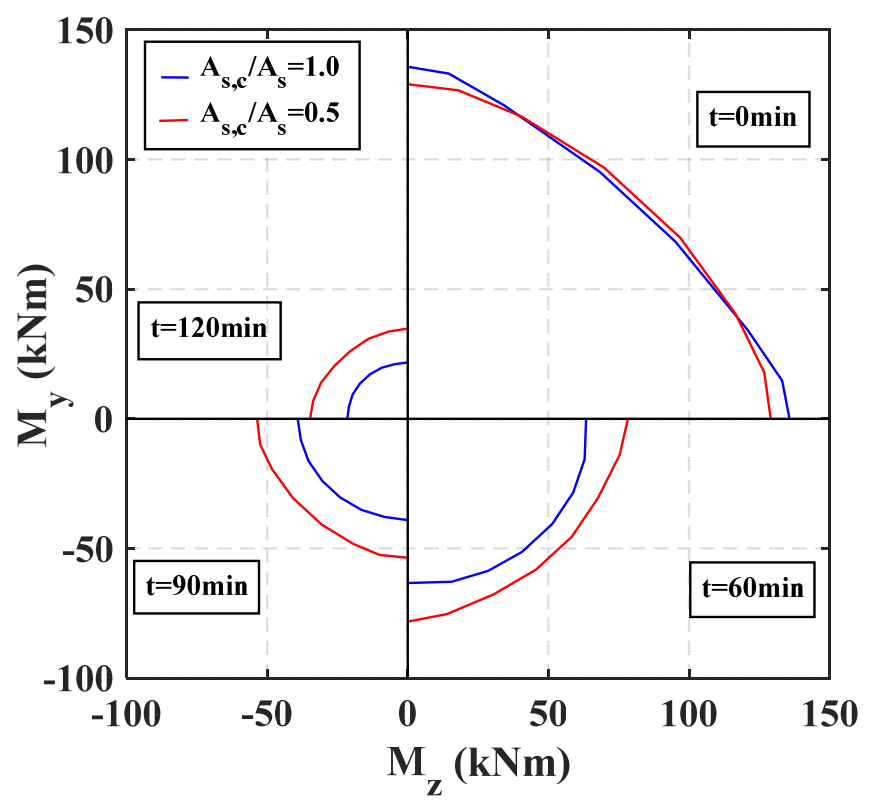

Fig. 10. Biaxial moment diagrams at different standard fire exposure times $(\mathrm{N}=1000 \mathrm{kN}$, corresponding to volumes in Fig. 9d)

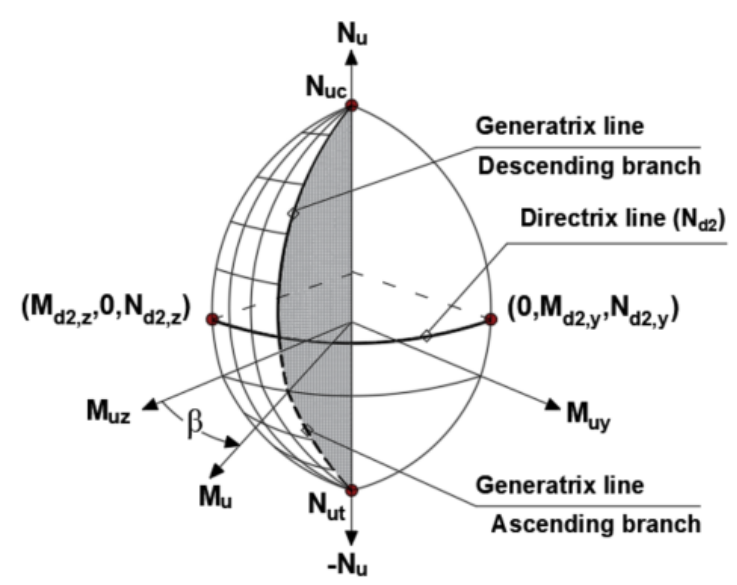

Fig. 11. Failure surface model 
D. L. peña, V. Albero, C. Ibáñez, A. Hospitaler. Sectional model for the fire evaluation of reinforced concrete columns subjected to biaxial bending. Engineering Structures 2021; 247: 113094. https://doi.org/10.1016/j.engstruct.2021.113094

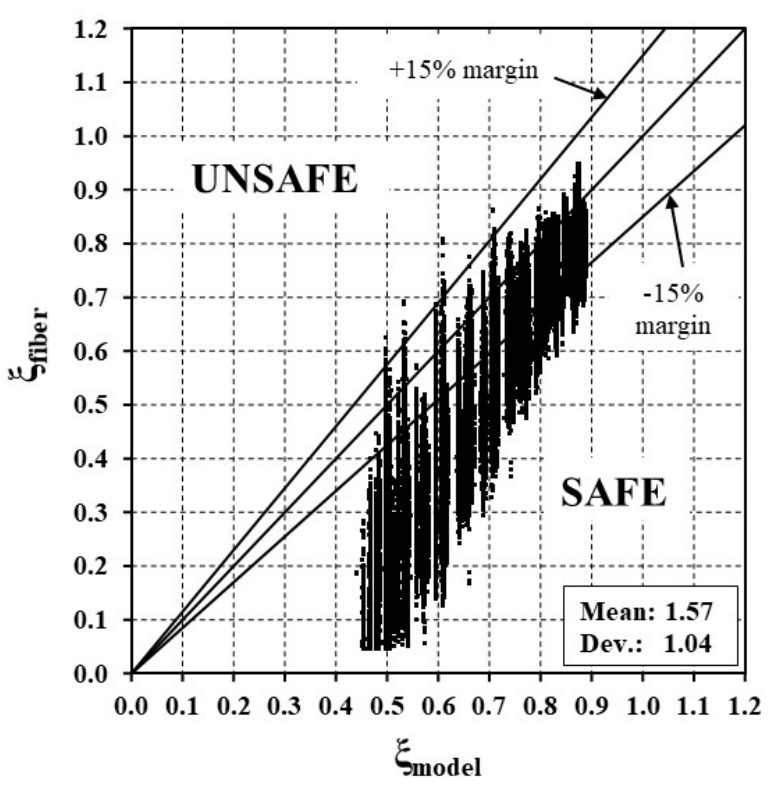

a)

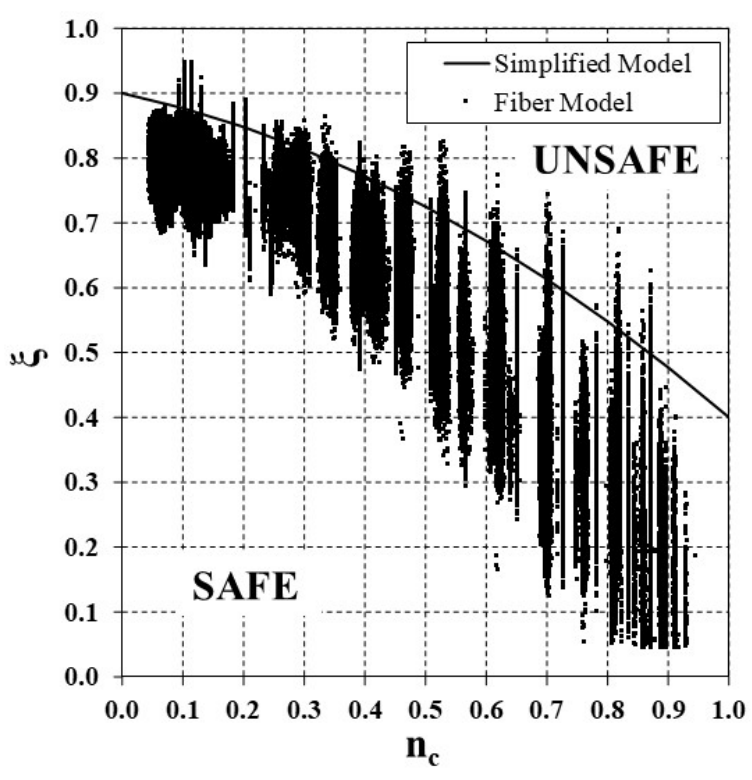

b)

Fig. 12. $\xi$-coefficient regression model: a) $\xi_{\text {fiber vs. }} \xi_{\text {model }}$ b) $\xi_{\text {model vs. }} \mathrm{n}_{\mathrm{c}}$ 
D. L. peña, V. Albero, C. Ibáñez, A. Hospitaler. Sectional model for the fire evaluation of reinforced concrete columns subjected to biaxial bending. Engineering Structures 2021; 247: 113094. https://doi.org/10.1016/j.engstruct.2021.113094
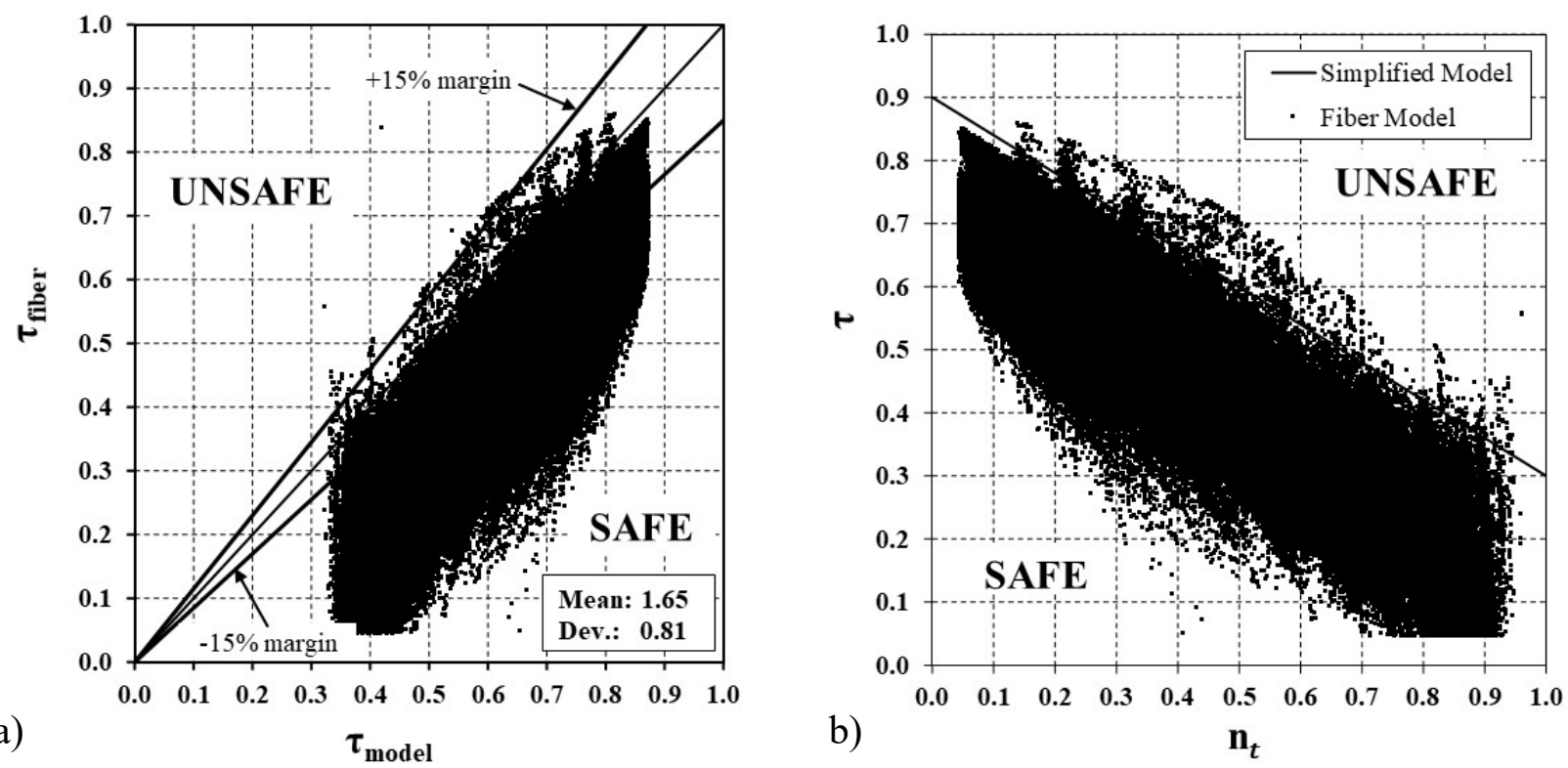

Fig. 13. $\tau$-coefficient regression model: a) $\tau_{\text {fiber }}$ vs. $\tau_{\text {model }}$; b) $\tau_{\text {model }}$ Vs. $n_{t}$ 
D. L. peña, V. Albero, C. Ibáñez, A. Hospitaler. Sectional model for the fire evaluation of reinforced concrete columns subjected to biaxial bending. Engineering Structures 2021; 247: 113094. https://doi.org/10.1016/j.engstruct.2021.113094
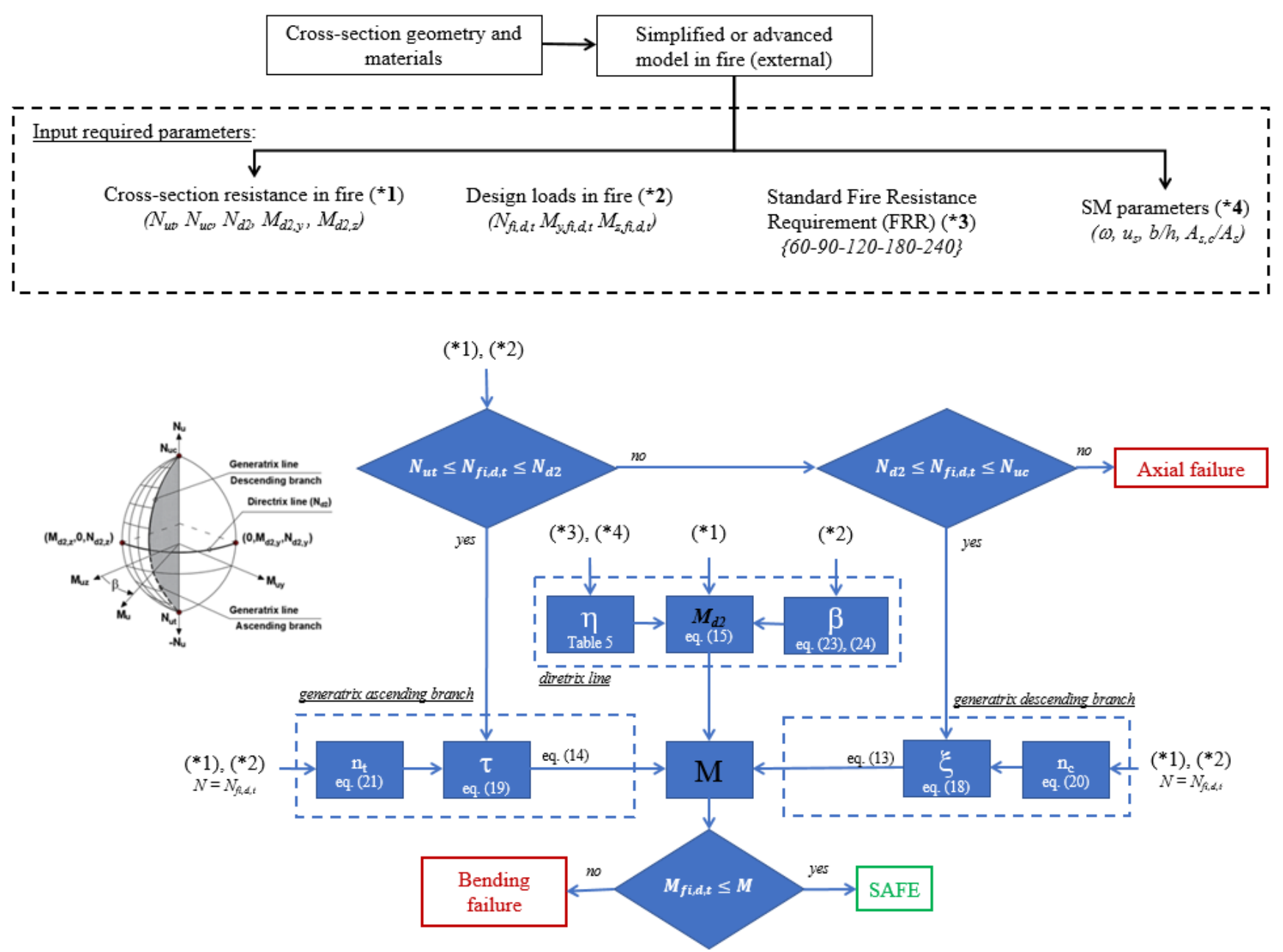

Fig. 14. Simplified model flowchart 
D. L. peña, V. Albero, C. Ibáñez, A. Hospitaler. Sectional model for the fire evaluation of reinforced concrete columns subjected to biaxial bending. Engineering Structures 2021; 247: 113094. https://doi.org/10.1016/j.engstruct.2021.113094

a) Room temperature $\& \mathrm{As}_{\mathrm{s}, \mathrm{c}} / \mathrm{A}_{\mathrm{s}}=1$

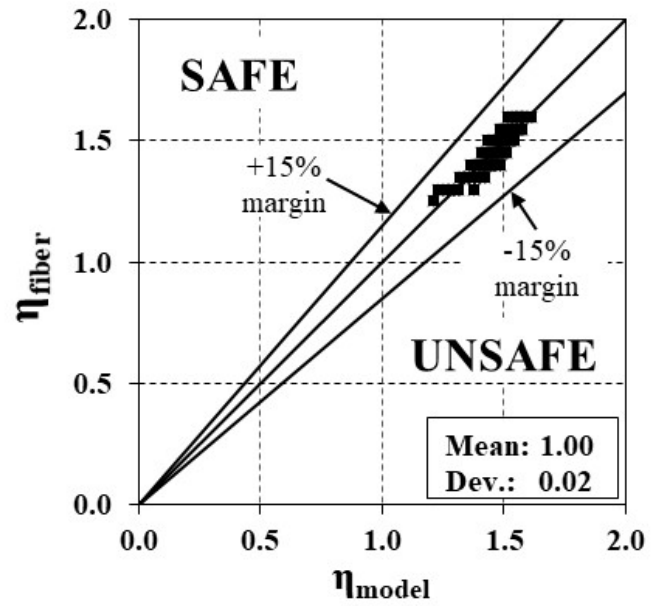

c) $t>0 \& \mathrm{~A}_{\mathrm{s}, \mathrm{c}} / \mathrm{A}_{\mathrm{s}}=1$

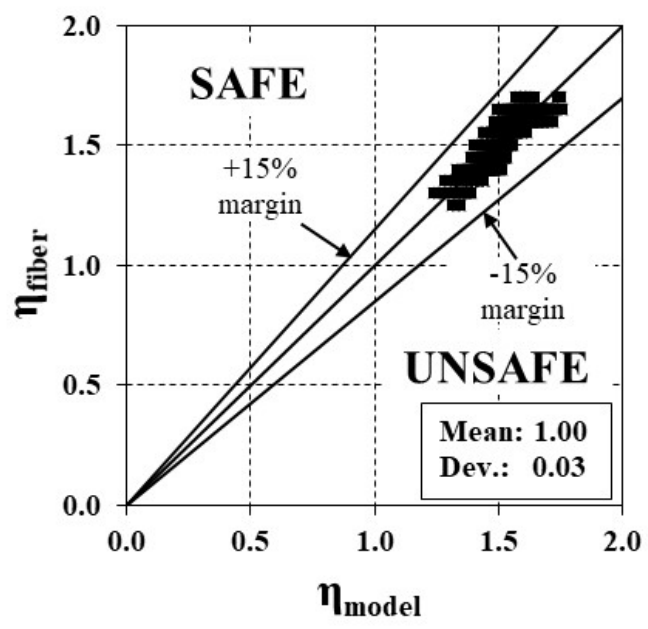

b) Room temperature $\& \mathrm{~A}_{\mathrm{s}, \mathrm{c}} / \mathrm{A}_{\mathrm{s}}<1$

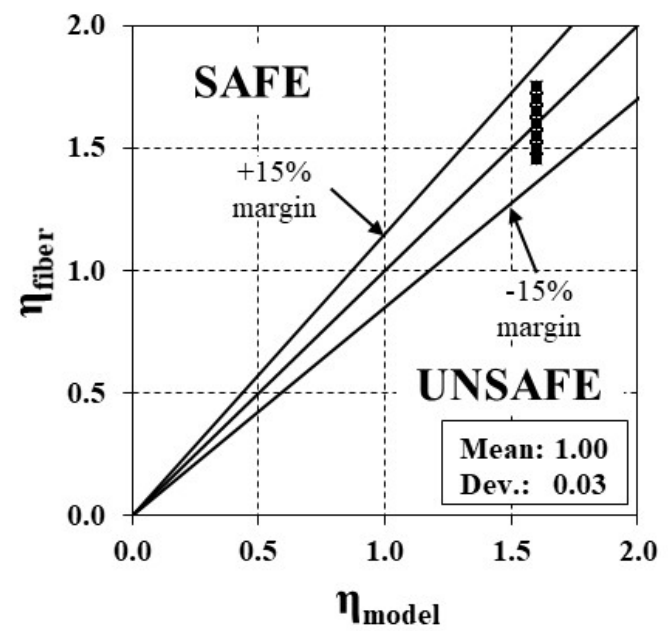

d) $t>0 \& \mathrm{~A}_{\mathrm{s}, \mathrm{c}} / \mathrm{A}_{\mathrm{s}}<1$

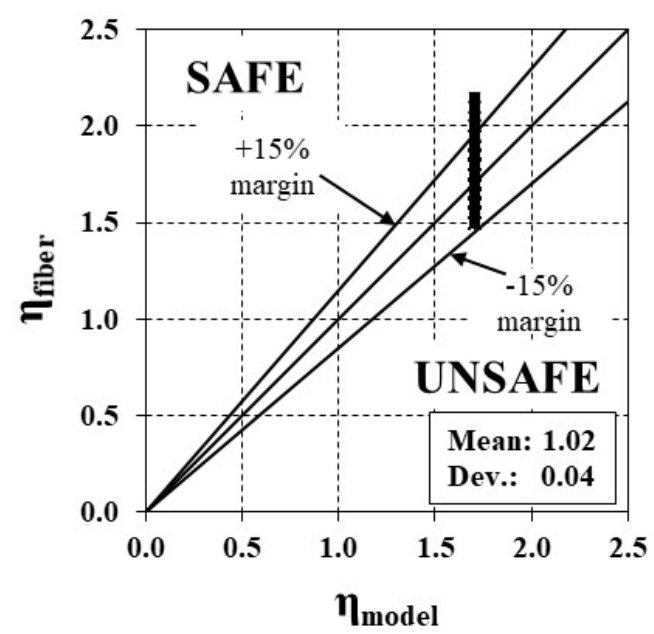

Fig. 15. $\eta$-coefficient regression model 
D. L. peña, V. Albero, C. Ibáñez, A. Hospitaler. Sectional model for the fire evaluation of reinforced concrete columns subjected to biaxial bending. Engineering Structures 2021; 247: 113094. https://doi.org/10.1016/j.engstruct.2021.113094

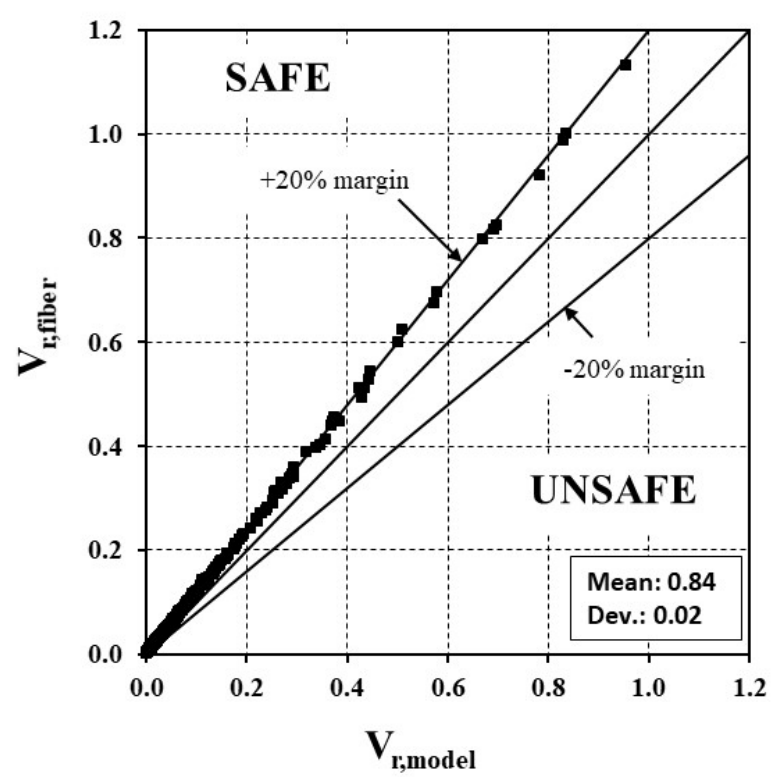

Fig. 16. Interaction surface volume ratio 
D. L. peña, V. Albero, C. Ibáñez, A. Hospitaler. Sectional model for the fire evaluation of reinforced concrete columns subjected to biaxial bending. Engineering Structures 2021; 247: 113094. https://doi.org/10.1016/j.engstruct.2021.113094

a)

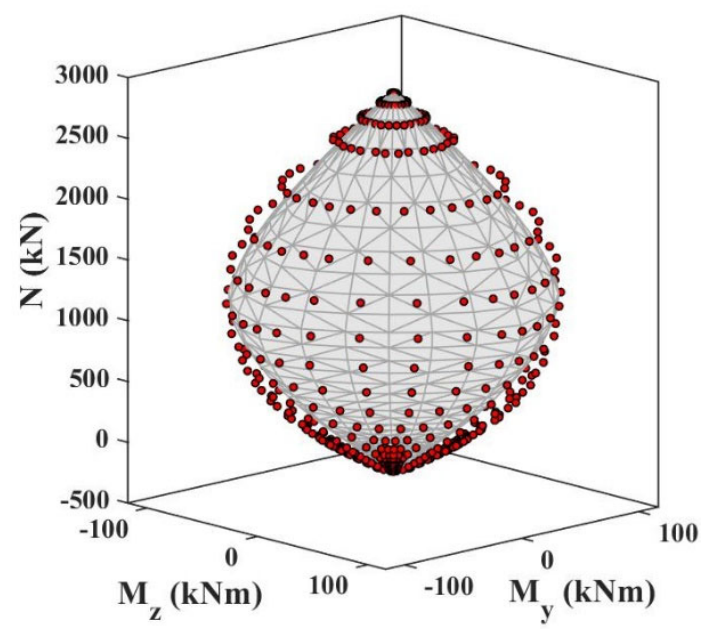

b)

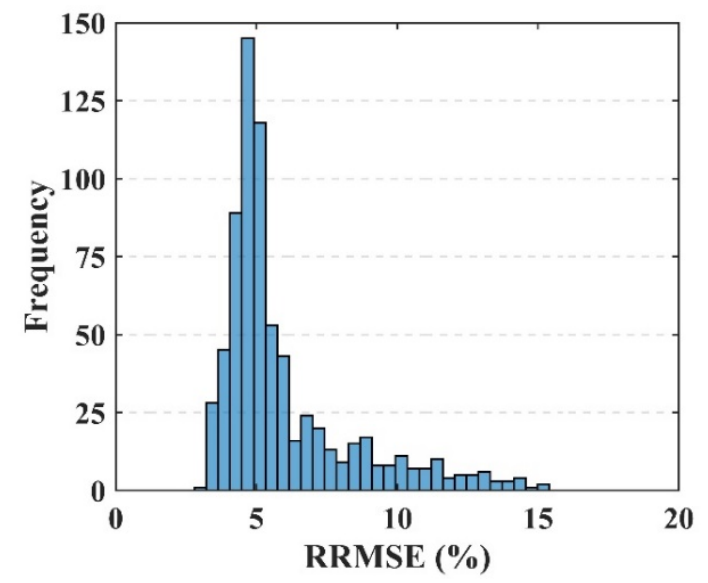

c)

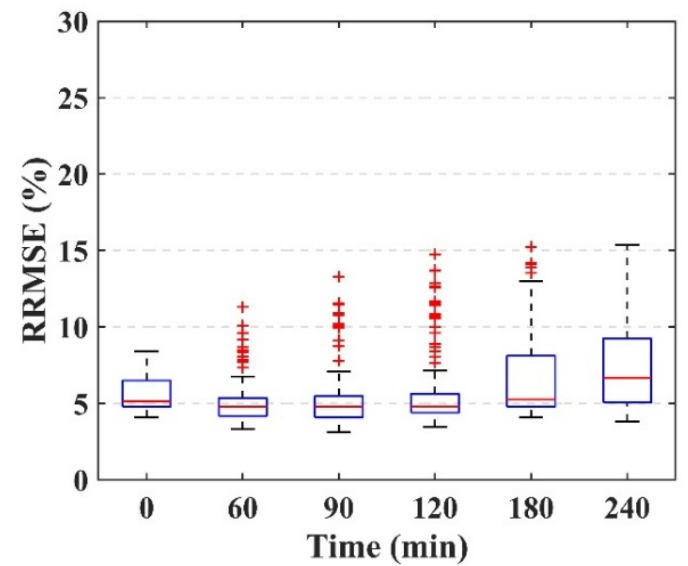

Fig. 17. RRMSE analysis for validation: a) Failure surface vs. points given by the fiber model; b) RRMSE histogram; c) RRMSE Box \& Whiskers 
D. L. peña, V. Albero, C. Ibáñez, A. Hospitaler. Sectional model for the fire evaluation of reinforced concrete columns subjected to biaxial bending. Engineering Structures 2021; 247: 113094. https://doi.org/10.1016/j.engstruct.2021.113094

a)

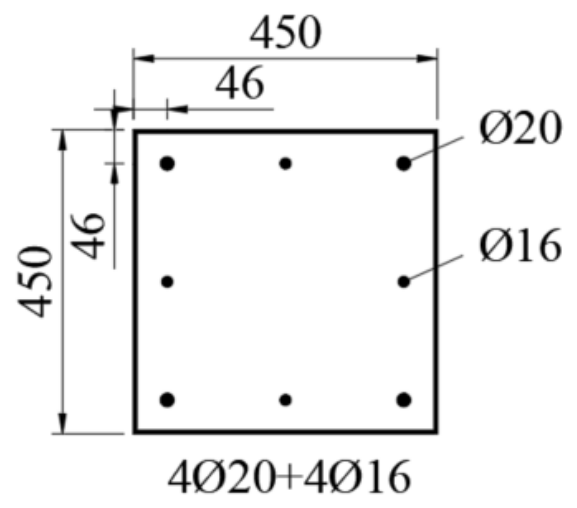

b)

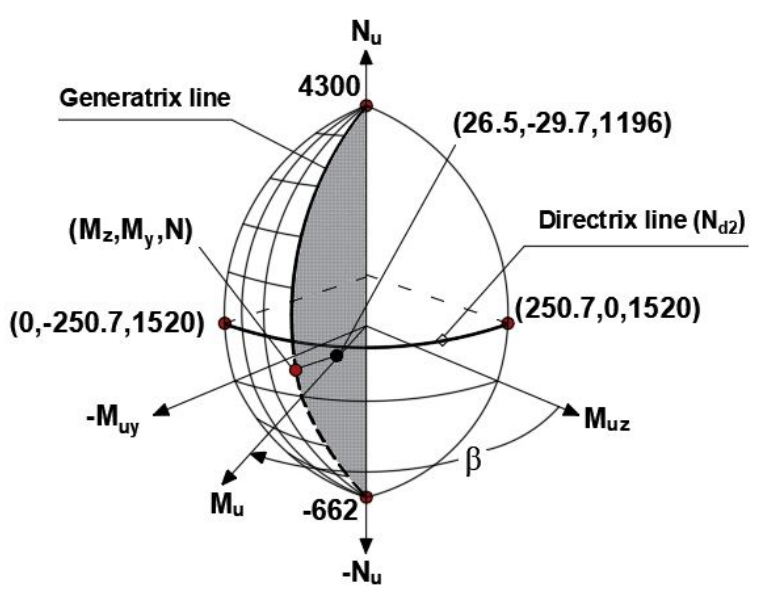

Fig. 18. Worked example: a) Column dimensions; b) Failure surface 
D. L. peña, V. Albero, C. Ibáñez, A. Hospitaler. Sectional model for the fire evaluation of reinforced concrete columns subjected to biaxial bending. Engineering Structures 2021; 247: 113094. https://doi.org/10.1016/j.engstruct.2021.113094

Table 1. Specimens used for the validation of the thermal model

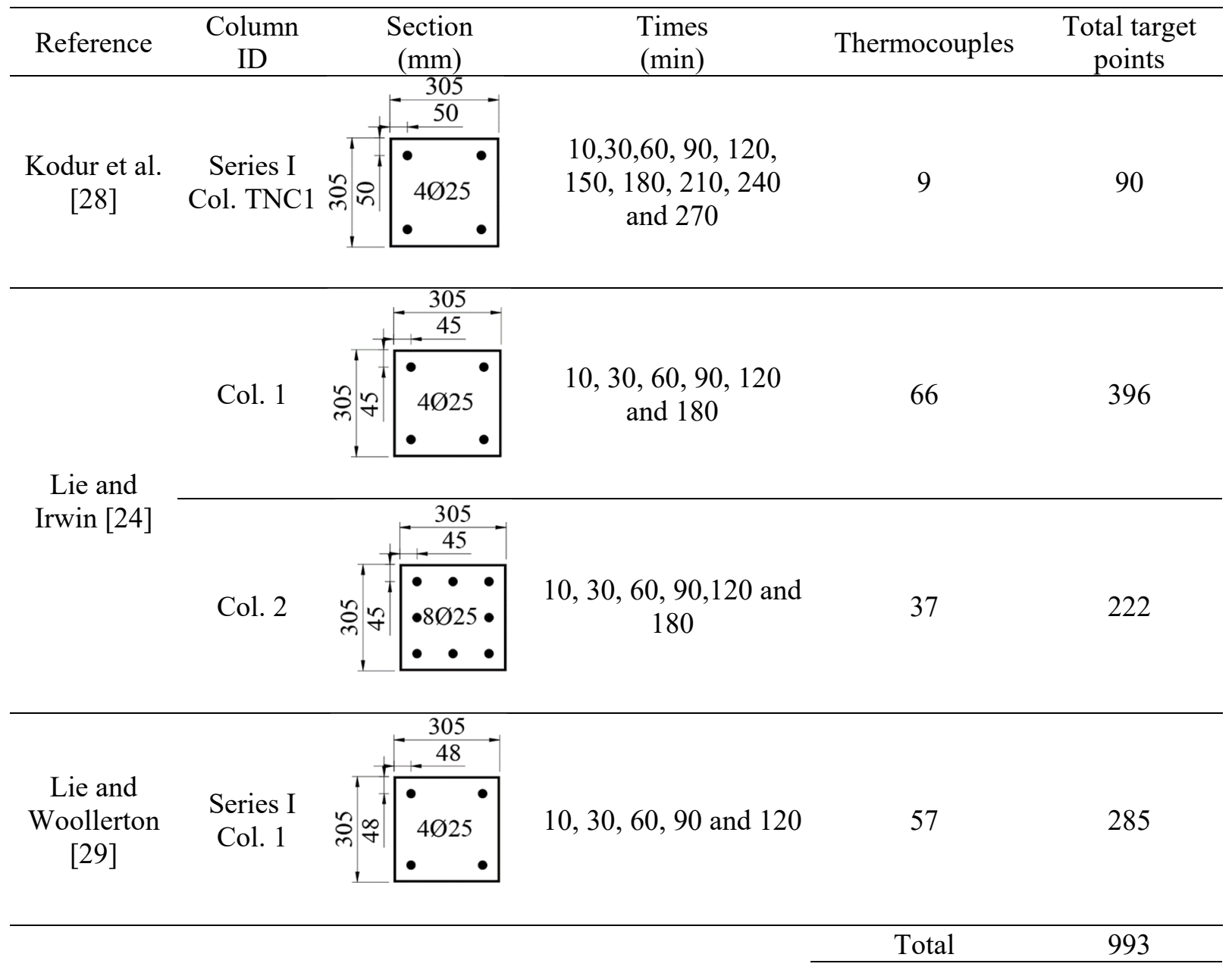

Table 2. Thermal model: mean error and SD

\begin{tabular}{clcccccc}
\hline \multirow{2}{*}{ Reference } & \multicolumn{2}{c}{ Column ID } & \multicolumn{2}{c}{$\mathrm{T}<300^{\circ} \mathrm{C}$} & \multicolumn{2}{c}{$\mathrm{T} \geq 300^{\circ} \mathrm{C}$} & \multicolumn{2}{c}{ All range of T } \\
\cline { 2 - 7 } & Mean & SD & Mean & SD & Mean & SD \\
\hline $\begin{array}{c}\text { Kodur et al. } \\
{[28]}\end{array}$ & Series I Col.TNC1 & 0.77 & 0.39 & 0.98 & 0.10 & 0.87 & 0.21 \\
\hline \multirow{2}{*}{\begin{tabular}{c} 
Lie and Irwin [24] \\
\cline { 2 - 7 }
\end{tabular}} & Col. 1 & 0.70 & 0.19 & 1.00 & 0.13 & 0.88 & 0.21 \\
\cline { 2 - 7 } & Col. 2 & 0.74 & 0.42 & 0.97 & 0.14 & 0.89 & 0.22 \\
\hline $\begin{array}{c}\text { Lie and Woollerton } \\
{[29]}\end{array}$ & Series I Col. 1 & 0.73 & 0.30 & 1.01 & 0.15 & 0.89 & 0.27 \\
\hline
\end{tabular}


D. L. peña, V. Albero, C. Ibáñez, A. Hospitaler. Sectional model for the fire evaluation of reinforced concrete columns subjected to biaxial bending. Engineering Structures 2021; 247: 113094. https://doi.org/10.1016/j.engstruct.2021.113094

Table 3. Specimens used in the fiber model validation for biaxial bending at ambient temperature, predicted values and calculated error

\begin{tabular}{|c|c|c|c|c|c|c|c|c|c|c|}
\hline Ref. & ID & $f_{c}(\mathrm{MPa})$ & $f_{y}(\mathrm{MPa})$ & $\omega$ & $\lambda$ & $\mathrm{x}(\mathrm{mm})$ & $\mathrm{y}(\mathrm{mm})$ & $\begin{array}{l}N_{\exp } \\
(\mathrm{kN})\end{array}$ & $\begin{array}{l}N_{\text {fiber }} \\
(\mathrm{kN})\end{array}$ & $\xi_{3 \mathrm{D}}$ \\
\hline \multirow{8}{*}{ 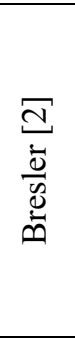 } & B-1 & 25.5 & 368.9 & 0.37 & 21 & 152 & 0 & 106.8 & 110.1 & 0.97 \\
\hline & B-2 & 26.9 & 368.9 & 0.35 & 21 & 76 & 0 & 266.9 & 283.6 & 0.94 \\
\hline & B-3 & 25.5 & 368.9 & 0.37 & 21 & 0 & 102 & 311.4 & 313.1 & 0.99 \\
\hline & B-4 & 31.7 & 368.9 & 0.30 & 21 & 0 & 203 & 142.3 & 132.1 & 1.08 \\
\hline & B-5 & 22.1 & 368.9 & 0.43 & 21 & 76 & 101 & 142.3 & 155.0 & 0.92 \\
\hline & B-6 & 25.5 & 368.9 & 0.37 & 21 & 152 & 203 & 75.6 & 77.8 & 0.97 \\
\hline & B-7 & 24.1 & 368.9 & 0.39 & 21 & 152 & 101 & 93.4 & 99.1 & 0.94 \\
\hline & B-8 & 24.8 & 368.9 & 0.38 & 21 & 76 & 203 & 106.8 & 104.9 & 1.02 \\
\hline \multirow{9}{*}{ 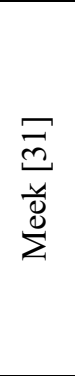 } & $\mathrm{N}^{0} 1$ & 38.6 & 354.4 & 0.32 & 42 & 18 & 19 & 411.5 & 430.0 & 0.96 \\
\hline & $\mathrm{N}^{0} 2$ & 33.5 & 354.4 & 0.37 & 42 & 14 & 25 & 338.1 & 363.7 & 0.93 \\
\hline & $\mathrm{N}^{0} 3$ & 37.4 & 354.4 & 0.33 & 42 & 12 & 25 & 400.3 & 404.7 & 0.99 \\
\hline & $\mathrm{N}^{\circ} 4$ & 36.9 & 354.4 & 0.34 & 42 & 15 & 24 & 389.2 & 397.6 & 0.98 \\
\hline & $\mathrm{N}^{0} 5$ & 37.4 & 354.4 & 0.33 & 42 & 0 & 27 & 400.3 & 420.5 & 0.95 \\
\hline & $\mathrm{N}^{\circ} 6$ & 33.1 & 354.4 & 0.38 & 42 & 10 & 28 & 333.6 & 360.5 & 0.93 \\
\hline & $\mathrm{N}^{0} 7$ & 33.1 & 354.4 & 0.38 & 42 & 14 & 29 & 333.6 & 340.7 & 0.98 \\
\hline & $\mathrm{N}^{\circ} 8$ & 37.2 & 354.4 & 0.34 & 42 & 8 & 23 & 398.1 & 434.8 & 0.92 \\
\hline & $\mathrm{N}^{\circ} 9$ & 31.9 & 354.4 & 0.39 & 42 & 25 & 26 & 318.1 & 300.3 & 1.06 \\
\hline \multirow{33}{*}{ 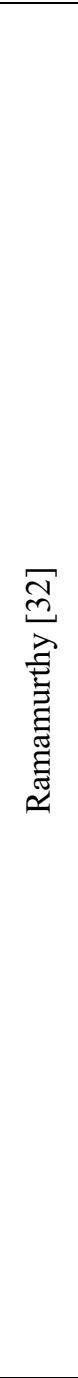 } & A-4 & 47.9 & 234.4 & 0.12 & 34 & 41 & 153 & 283.6 & 229.2 & 1.24 \\
\hline & A-5 & 42.7 & 234.4 & 0.14 & 34 & 48 & 178 & 235.8 & 179.3 & 1.32 \\
\hline & A-6 & 40.3 & 234.4 & 0.14 & 34 & 53 & 203 & 171.9 & 141.4 & 1.22 \\
\hline & A-8 & 31.9 & 234.4 & 0.18 & 34 & 28 & 76 & 4756.0 & 506.0 & 0.94 \\
\hline & A-9 & 46.2 & 234.4 & 0.12 & 34 & 55 & 152 & 280.24 & 217.8 & 1.29 \\
\hline & A-12 & 49.6 & 234.4 & 0.12 & 34 & 103 & 178 & 170.14 & 161.0 & 1.06 \\
\hline & A-13 & 20.9 & 234.4 & 0.28 & 34 & 102 & 152 & 164.58 & 138.7 & 1.19 \\
\hline & A-14 & 29.6 & 234.4 & 0.19 & 34 & 102 & 203 & 160.1 & 118.8 & 1.35 \\
\hline & A-15 & 23.7 & 234.4 & 0.24 & 34 & 90 & 90 & 266.9 & 231.1 & 1.16 \\
\hline & B-1 & 32.4 & 322.6 & 0.38 & 34 & 21 & 79 & 628.98 & 669.6 & 0.94 \\
\hline & B-2 & 28.6 & 322.6 & 0.43 & 34 & 19 & 47 & 771.8 & 853.5 & 0.90 \\
\hline & B-3 & 37.2 & 322.6 & 0.33 & 34 & 51 & 88 & 533.8 & 556.4 & 0.96 \\
\hline & B-4 & 35.6 & 322.6 & 0.35 & 34 & 64 & 110 & 395.9 & 426.6 & 0.93 \\
\hline & B-6 & 30.6 & 322.6 & 0.41 & 34 & 65 & 65 & 500.4 & 550.0 & 0.91 \\
\hline & B-7 & 32.7 & 322.6 & 0.38 & 34 & 72 & 72 & 516.0 & 509.2 & 1.01 \\
\hline & B-8 & 37.9 & 322.6 & 0.33 & 34 & 102 & 102 & 369.8 & 370.9 & 1.00 \\
\hline & C-1 & 34.6 & 275.8 & 0.35 & 46 & 10 & 37 & 464.8 & 529.19 & 0.88 \\
\hline & C-1(a) & 41.1 & 275.8 & 0.29 & 46 & 10 & 37 & 569.4 & 597.7 & 0.95 \\
\hline & $\mathrm{C}-3$ & 32.2 & 275.8 & 0.25 & 46 & 10 & 37 & 460.4 & 504.5 & 0.91 \\
\hline & C-4 & 26.7 & 275.8 & 0.38 & 46 & 23 & 40 & 378.1 & 388.2 & 0.97 \\
\hline & $C-5$ & 27.6 & 275.8 & 0.45 & 46 & 15 & 26 & 506.0 & 507.5 & 1.00 \\
\hline & C-6 & 34.47 & 275.8 & 0.44 & 46 & 43 & 43 & 350.3 & 350.7 & 1.00 \\
\hline & R-138 & 25.9 & 275.8 & 0.35 & 46 & 76 & 76 & 138.3 & 126.4 & 1.09 \\
\hline & R-238 & 34.5 & 275.8 & 0.26 & 46 & 76 & 76 & 160.1 & 142.5 & 1.12 \\
\hline & R-338 & 36.2 & 275.8 & 0.20 & 46 & 97 & 97 & 118.8 & 105.5 & 1.13 \\
\hline & R-438 & 29.6 & 275.8 & 0.19 & 46 & 102 & 152 & 71.2 & 67.4 & 1.06 \\
\hline & D-1 & 35.1 & 322.6 & 0.42 & 31 & 25 & 38 & 785.1 & 881.3 & 0.89 \\
\hline & D-2 & 28.2 & 322.6 & 0.39 & 35 & 56 & 85 & 400.3 & 414.0 & 0.97 \\
\hline & D-3 & 27.1 & 322.6 & 0.55 & 31 & 76 & 114 & 311.4 & 298.4 & 1.04 \\
\hline & D-4 & 27.9 & 322.6 & 0.53 & 31 & 32 & 32 & 680.6 & 729.4 & 0.93 \\
\hline & D-5 & 34.3 & 322.6 & 0.43 & 31 & 81 & 81 & 378.1 & 367.1 & 1.03 \\
\hline & D-6 & 26.5 & 322.6 & 0.56 & 31 & 79 & 46 & 400.3 & 386.5 & 1.04 \\
\hline & E-1 & 26 & 322.6 & 0.43 & 23 & 57 & 114 & 464.8 & 462.2 & 1.01 \\
\hline
\end{tabular}


D. L. peña, V. Albero, C. Ibáñez, A. Hospitaler. Sectional model for the fire evaluation of reinforced concrete columns subjected to biaxial bending. Engineering Structures 2021; 247: 113094. https://doi.org/10.1016/j.engstruct.2021.113094

\begin{tabular}{cccccccccc} 
E-2 & 23.8 & 322.6 & 0.47 & 23 & 76 & 152 & 311.4 & 340.3 & 0.92 \\
E-3 & 30.8 & 322.6 & 0.36 & 23 & 86 & 86 & 435.9 & 411.2 & 1.06 \\
E-4 & 27.6 & 322.6 & 0.40 & 23 & 66 & 38 & 542.7 & 566.2 & 0.96 \\
F-1 & 32.5 & 291.9 & 0.26 & 31 & 15 & 55 & 600.5 & 692.7 & 0.87 \\
F-3 & 20 & 291.9 & 0.43 & 31 & 32 & 48 & 384.8 & 441.0 & 0.87 \\
F-5 & 29.6 & 291.9 & 0.29 & 31 & 40 & 40 & 466.0 & 537.9 & 0.87 \\
G-1 & 36.6 & 291.9 & 0.17 & 23 & 20 & 74 & 827.4 & 899.0 & 0.92 \\
G-2 & 28 & 291.9 & 0.23 & 23 & 33 & 123 & 418.1 & 460.5 & 0.91 \\
G-3 & 24 & 291.9 & 0.27 & 23 & 34 & 68 & 507.1 & 574.7 & 0.88 \\
G-4 & 41.4 & 291.9 & 0.15 & 23 & 68 & 136 & 333.6 & 356.3 & 0.94 \\
\hline
\end{tabular}

Table 4. List of parameters

\begin{tabular}{lc}
\hline \multicolumn{1}{c}{ Parameter } & Values \\
\hline Aspect ratio $(b / h)$ & $1-1.33-2$ \\
$f_{c}(\mathrm{MPa})$ & $25-35-40-50$ \\
$u_{s}(\mathrm{~mm})$ & $25-35-45-55-65$ \\
FRR (min) & $0-60-90-120-180-240$ \\
Reinforcement arrangement $\left(A_{s, c} / A_{s}\right)$ & $0.14 \leq A_{s, c} / A_{s} \leq 1$ \\
Reinforcement ratio $(\omega)$ & $0.05 \leq \omega \leq 0.84$ \\
\hline
\end{tabular}

Table 5. Bresler's exponents proposal

\begin{tabular}{ccc}
\hline & $A_{s, c} / A_{s}=1$ & $A_{s, c} / A_{s}<1$ \\
\hline Room Temperature & $\eta=1.60+\left(0.2 u_{s}-85 \omega-5 \frac{b}{h}\right) 10^{-2} \geq 1$ & $\eta=1.60$ \\
High Temperature & $\eta=1.68+\left(54 t-558 \omega-3.6 u_{s}\right) 10^{-3} \geq 1$ & $\eta=1.70$ \\
$\mathrm{t}>0$ & & \\
\hline
\end{tabular}

Table 6. Loads considered at the example

\begin{tabular}{lccc}
\hline Load & $N(\mathrm{kN})$ & $M_{z}(\mathrm{kNm})$ & $M_{y}(\mathrm{kNm})$ \\
\hline Self-Weight (SW) & 575 & 8.8 & -17.0 \\
Dead load (D) & 473 & 9.4 & -5.4 \\
Live load (L) & 211 & 11.8 & -10.4 \\
\hline
\end{tabular}


D. L. peña, V. Albero, C. Ibáñez, A. Hospitaler. Sectional model for the fire evaluation of reinforced concrete columns subjected to biaxial bending. Engineering Structures 2021; 247: 113094. https://doi.org/10.1016/j.engstruct.2021.113094 
D. L. peña, V. Albero, C. Ibáñez, A. Hospitaler. Sectional model for the fire evaluation of reinforced concrete columns subjected to biaxial bending. Engineering Structures 2021; 247: 113094. https://doi.org/10.1016/j.engstruct.2021.113094

\section{LIST OF FIGURE CAPTIONS}

Fig. 1a) RC industrial building after a fire; b) Column after a fire (corner spalling); c) Lateral column after a fire

Fig. 2 Fiber numerical model flowchart

Fig. 3 Cross-section discretisation for the thermal analysis

Fig. 4 Fiber model a) Cross-section discretisation and strain distribution; b) 3D failure surface Fig. 5 Experimental vs. fiber model predictions: a) Series I TNC1 [28]; b) Col.1 [24]; c) Col. 2 [24]; d) Series I Col.1 [29]

Fig. 6 Temperature-time curves: a) Series I TNC1 [28]; b) Col.1 [24]; c) Col. 2 [24]; d) Series I Col.1 [29]

Fig. 7 a) Experimental vs. fiber model predictions; b) Prediction error

Fig. 8 Uniaxial interaction diagrams for different fire exposure times

Fig. 9 Results from parametric study

Fig. 10 Biaxial moment diagrams at different standard fire exposure times $(\mathrm{N}=1000 \mathrm{kN}$, corresponding to volumes in Fig. 9d)

Fig. 11 Failure surface model

Fig. $12 \xi$-coefficient regression model: a) $\xi_{\text {fiber vs. }} \xi_{\text {model }}$ b) $\xi_{\text {model vs. }} \mathrm{n}_{\mathrm{c}}$

Fig. $13 \tau$-coefficient regression model: a) $\tau_{\text {fiber }}$ vs. $\tau_{\text {model }}$; b) $\tau_{\text {model }}$ vs. $n_{t}$

Fig. 14 Simplified model flowchart

Fig. $15 \eta$-coefficient regression model

Fig. 16 Interaction surface volume ratio

Fig. 17 RRMSE analysis for validation: a) Failure surface vs. points given by the fiber model;

b) RRMSE histogram; c) RRMSE Box \& Whiskers

Fig. 18 Worked example: a) Column dimensions; b) Failure surface 
D. L. peña, V. Albero, C. Ibáñez, A. Hospitaler. Sectional model for the fire evaluation of reinforced concrete columns subjected to biaxial bending. Engineering Structures 2021; 247: 113094. https://doi.org/10.1016/j.engstruct.2021.113094

\section{LIST OF TABLE CAPTIONS}

Table 1 Specimens used for the validation of the thermal model

Table 2 Thermal model: mean error and SD

Table 3 Specimens used in the fiber model validation for biaxial bending at ambient temperature, predicted values and calculated error

Table 4 List of parameters

Table 5 Bresler's exponents proposal

Table 6 Loads considered at the example 